\title{
Ionic liquids as an enabling tool to integrate reaction and separation processes
}

\author{
Rocio Villa, ${ }^{a}$ Elena Alvarez, ${ }^{a}$ Raul Porcar, ${ }^{b}$ Eduardo Garcia-Verdugo, ${ }^{b}$ Santiago \\ V. Luis, ${ }^{b}$ and Pedro Lozano* ${ }^{a}$
}

\begin{abstract}
The development of advanced processes able to directly provide pure products by integrating chemical transformations, product separation and recovery and reuse of the solvent and the catalytic phases by straightforward and smart approaches, is a key feature to build green chemical processes. The unique properties of ILs, one of the key enabling technologies, can lead, when combined with (bio)catalysts, to amazing synergies not only improving the catalytic efficiency (i.e. improved activity and enantioselectivity, enhanced stability, etc.), but also allowing the design of smarts approaches for product separation (e.g. IL/scCO $\mathrm{s}_{2}$ biphasic reactors, membrane reactors, nanodrop systems, microfluidic devices, supported ionic liquid phases, sponge-like ionic liquids, etc.), incorporating the full recovery and reuse of the catalyst and the ILs phase. This tutorial review highlights representative examples of ILs-based systems integrating reaction/separation as a tool for the development of sustainable chemical processes leading to clean and pure chemical products.
\end{abstract}

\section{Ionic liquids for clean chemical processes.}

The application of the principles of green chemistry (i.e. prevention, atom economy, less hazardous chemical syntheses, safer solvents and auxiliaries, etc. $)^{\mathbf{1 , 2}}$ and specially the development of new and highly efficient (bio)catalysts have push forward the improvement of greener chemical processes driving the construction of clean chemical industries. ${ }^{\mathbf{3}, 4}$ These green chemical approaches must not only consider the preparation of the required products, regardless of their complexity, but also the entire process including product separation and purification, the recovery and the reuse of catalysts and reaction media, the energy consumption, the toxicity of solvents and reagents, etc., all these aspects defining the overall environmental impact. ${ }^{5}$

Solvents provide a major contribution to the environmental performance of chemical processes in terms of health, safety or air, water and land impact, but they also significantly define the process cost. ${ }^{6}$ They are essential auxiliary materials in chemical synthesis, acting as media for mass and heat-transport, for reaction and for product separation. Already in 1733, Hermannus Boerhave stated: "Besides the four elements fire, water, air and soil we must consider a fifth one, the solvent, which is essential for chemists in conducting all their beautiful reactions". 7 The most popular solvents for chemical processes are volatile organic compounds (VOCs), which account for about $80-90 \%$ of the total mass used in any organic reaction, and $70-85 \%$ of the waste produced. ${ }^{\mathbf{8} 9}$ The use of some of the most traditional organic solvents (e.g. $\mathrm{CH}_{2} \mathrm{Cl}_{2}, \quad N, N$ dimethylformamide (DMF) and $N$-methyl-2-pyrrolidone (NMP), etc.) is associated with VOCs pollution, which represents a clear handicap for the development of sustainable chemical processes. There are many key criteria, such as product separation and purification, the recovery and reuse of solvents, energy consumption, environmental impact, toxicity of solvents, reagents and undesired by-product, etc., to be taken into account for building clean chemical processes. Because of the volatile character of organic solvents, they can be only partially recovered for further reuse. Besides, this requires protocols with high-energy consumption, contributing to increase their environmental footprint.

In the search for alternative environmentally benign solvents with lower impact, which could be easily be recovered/recycled, different approaches have been taken. ${ }^{\mathbf{1 0 , 1 1 , 1 2 , 1 3 , 1 4}}$ The substitution of traditional organic solvents by supercritical fluids based in non-toxic compounds such as $\mathrm{CO}_{2}$ or water is an industrial reality being used to process tons of chemical products word-wide. ${ }^{\mathbf{1 5}, 16}$ The design, synthesis and application of new families of organic solvents derived from bio-renewable feedstocks (e.g. 2-MeTHF, ${ }^{17} \gamma$-valerolactone, ${ }^{\mathbf{1 8}}$ cyrene, ${ }^{19}$ etc.) constitute emerging substitutes because of their better environmental, health and safety parameters. ${ }^{\mathbf{2 0}}$

Headed by their non-volatile character, ionic liquids (ILs) are the non-aqueous green solvents having received more attention worldwide. They are liquids at temperatures lower than $100{ }^{\circ} \mathrm{C}$, are composed entirely by ions, and their use has led to a green chemical revolution because of their unique array of physical-chemical properties (i.e. low vapour pressure, nonflammable nature, high ionic conductivity, high thermal and chemical stabilities, excellent solvent power towards many substrates, including gases, etc.).21. Typical ILs used in biocatalytic processes are based on organic cations, e.g. dialkylimidazolium, tetraalkylammonium, or phosphonium, etc., paired with anions that have a strongly delocalized charge (e.g. $\left[\mathrm{PF}_{6}\right],\left[\mathrm{BF}_{4}\right]$, bistriflimide or $\mathrm{NTf}_{2}$ ), etc.). In contrast to conventional molecular solvents, the non-volatile character of ILs permits their full recovery for further reuse. By the appropriate choice of cation and anion, the polarity and hydrophilicity/hydrophobicity of ILs can be tuned, modifying 
their miscibility with molecular solvents (e.g. water, organic solvents, etc.), which has been applied for developing useful approaches for products recovery from the reaction mixture. ${ }^{22,23}$ Although ILs cannot be considered as fully innocuous solvents in terms of environmental impact and toxicity when considering their overall Life Cycle Assessment (LCA), ${ }^{\mathbf{2 4}, 25}$ their unique properties make them ideal solvents for numerous chemical applications. ${ }^{\mathbf{2 6 , 2 7}}$ In this context, the use of biocompatible ionic liquids (Bio-ILs), as an eco- and biofriendly family of ionic liquids (ILs), has recently been reported in applications ranging from the electrochemical to the biomedical fields. The strategies for their applications include their synthesis by using molecules from bio-renewable sources, as a basis for both the anionic (e.g. fatty acids carboxylates, lactate, levulinate, etc.), and cationic (e.g. choline, lignin derivatives, etc.) counterparts of the Bio-ILs structure, as well as integrated studies on solvent properties and their impact on the environment and health safety, as it has been recently reviewed. ${ }^{28}$

Another unique future of ILs concerns their excellent suitability as reaction media for chemical transformations, because of the exceptional level of activity and stability provided to (bio)catalysts, e.g. enzymes, metal nanoparticles (MNPS) etc. ${ }^{22,29}$ As an example for biocatalysts, it was reported how water-immiscible ILs (e.g. 1-butyl-3methylimidazolium bis(trifluoromethylsulfonyl)imide, [Bmim][NTf ${ }_{2}$; $\quad$ butyltrimethylammonium bis(trifluoromethylsulfonyl)imide, [Btma][NTf 2 , etc.) provide an appropriate microenvironment to enzymes at low water environments, because of the preservation of the essential hydration shell, as demonstrated by circular dichroism and fluorescence spectroscopies studies on the structure of different proteins, e.g. monellin, ${ }^{30 \mathrm{a}} \alpha$-chymotrypsin ${ }^{30 \mathrm{~b}}$ and Candida antarctica lipase $\mathrm{B}$ (CALB). ${ }^{30 c}$

By combining the advantages of selective (bio)catalytic transformations with the unique properties of ILs, positive synergies can be obtained, pushing towards the development of clean chemical processes, ${ }^{\mathbf{4 b}, 29}$ where the full recovery and reuse of ILs is key. ${ }^{31}$ These unique ILs properties has been exploited to design smart processes integrating the (bio)catalytic transformation of substrates with the selective separation of the products, as well as the full recovery and reuse of the catalytic IL-phase by following straightforward processes for different approaches (see Fig. 1)

Thus, the non-volatile character of ILs with respect to the high vapour pressure of many molecular compounds (i.e.

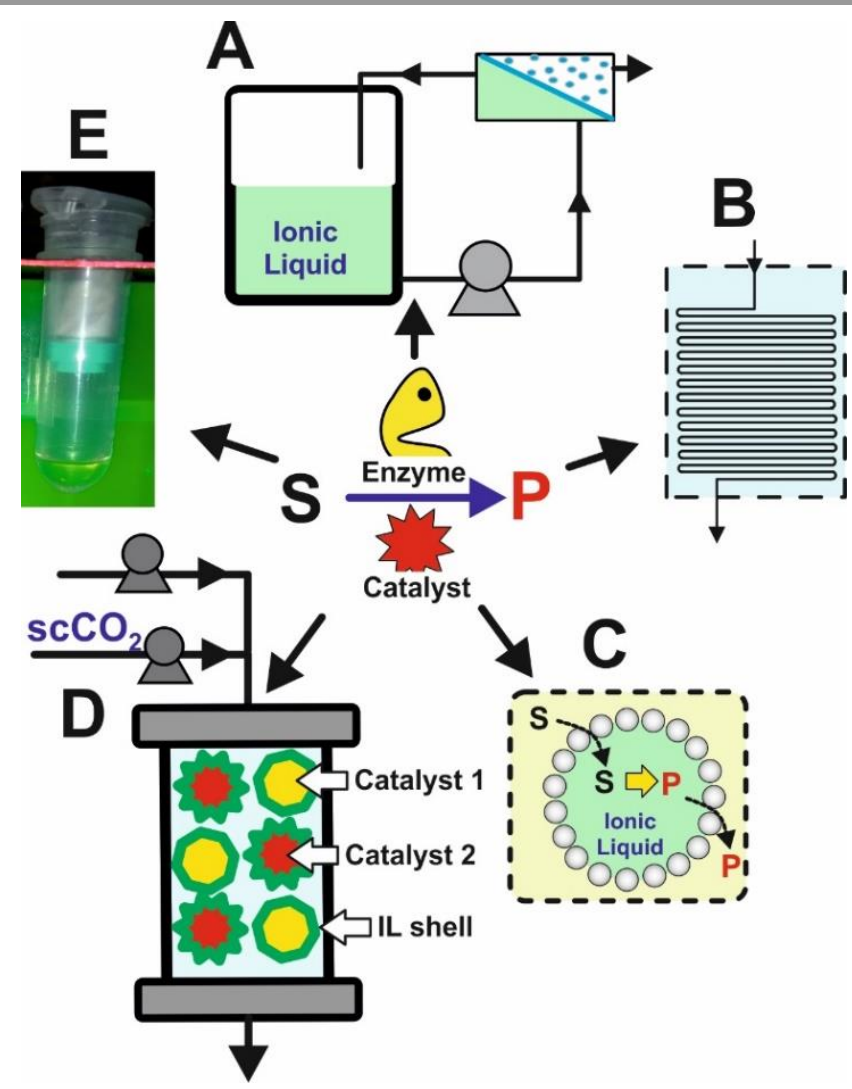

Fig. 1. Schematic representation of several approaches using ILs as an enabling tool for integrating reaction / separation processes. A, membrane reactors; B microfluidic devices; C, droplet Pickering emulsion microsystems; D, IL/ $\mathrm{scCO}_{2}$ biphasic reactors using supported ionic liquid phases; and $\mathrm{E}$, Sponge-like ionic liquids.

flavour molecules) can be exploited to design integrated reaction/separation systems based on membrane technologies (Fig. 1A). ${ }^{32}$ Additionally, their phase behaviour in the presence of molecular solvents at liquid or supercritical states has been also key for the development of integrated reaction/separation approaches based on multiphasic systems. Because of the nonmiscibility of ILs with many molecular liquid solvents (i.e. octane), microfluidic devices ${ }^{33}$ (Fig. 1B) and droplet Pickering emulsions (Fig. 1C), have been reported as enabling tools for integrated reaction/separation. It should also be noted that ILs and $\mathrm{scCO}_{2}$ form biphasic systems at any conditions. $\mathrm{scCO}_{2}$ is highly soluble in the IL-phase, while the same IL is not measurably soluble in the $\mathrm{scCO}_{2}$ phase. ${ }^{34}$ This genuine compatibility of ILs with $\mathrm{scCO}_{2}$, was also observed in the case of ionic liquids covalently attached onto solid polymers (Supported Ionic Liquid-Like Phases, SILLPs) ${ }^{35}$ used to design continuous flow catalytic systems integrating transformation and separation steps (Fig. 1D). ${ }^{36}$

Hydrophobic ILs based on cations with long alkyl sidechains are temperature switchable ionic liquid/solid phases that behave as sponge-like systems (Sponge-Like Ionic Liquids, SLILs). These SLILs have been shown as exceptional reaction media for biocatalytic reactions at temperatures higher than their melting point. Subsequently, these systems permit the 
easy separation of nearly pure products by using centrifugation/filtration approaches on the solid reaction system obtained after cooling (Fig. 1 E). ${ }^{37}$ All these approaches summarised in Fig 1 are explained in the different sections of this tutorial review.

This tutorial review aims to illustrate some significant examples highlighting how the different these new synthetic platforms based on different technological "green tools" can be exploited to integrate in a single process the reaction, separation of the products and recovery/reuse of the catalytic IL-based systems.

\section{Multiphase (bio)catalytic systems based on IL technology}

The concept of multiphase (bio)catalytic systems is based on using (bio)catalysts immobilized in one phase (working phase), while substrates and products reside largely in another liquid, gas or supercritical phase (extractive phases). The simplest of such a two-phase approach suitable for carrying out a target chemical transformation involves the suspension of a (bio)catalyst immobilized onto a solid support in a liquid phase containing the substrates. The catalyst phase can be easily recovered by simple decantation or filtration, thus enabling the isolation of the pure product and the easy recycling of the catalyst phase. $^{\mathbf{3 8}}$

In the case of ILs, their solvent properties and accordingly their miscibility/non-miscibility with additional substance or solvents can be tuned by selecting the appropriate combination of cation and anion. This interesting feature has been widely used for developing biphasic ILs-liquid systems (ILs-L) allowing the integration of reaction and separation. It is relatively easy to obtain ILs non-miscible with most hydrophobic organic solvents (e.g. ether, hexanes, $\mathrm{CH}_{2} \mathrm{Cl}_{2}$, etc.), thus providing a simple approach for two-phase ILorganic solvent systems. The selective oxidation of alcohols to aldehydes and ketones by a ruthenium catalyst in $[\mathrm{Bmim}]\left[\mathrm{NTf}_{2}\right],{ }^{39}$ or the lipase-catalysed kinetic resolution of 5phenyl-1-penten-3-ol in 1-butyl-3-methylimidazolium hexafluorophosphate, $[\mathrm{Bmim}]\left[\mathrm{PF}_{6}\right],{ }^{40}$ can be taken as representative examples of such systems.

In the search of greener ILs-L systems able to integrate catalysis and product separation processes, the use of thermosreversible aqueous biphasic systems (ABS) represents an interesting alternative. ${ }^{\mathbf{4 1}}$ In these systems the organic phase is substituted by a less toxic solvent as water. Besides, under certain conditions, the ABS forms a homogeneous mixture with the reactants and products at the temperature of the reaction but separates from them afterwards at a different temperature. Some ILs/aqueous solvent mixtures display an upper critical solution temperature (UCST) whereas others present a lower critical solution temperature (LCST). ${ }^{\mathbf{4 2 , 4 3}}$ These temperaturedependent phase transitions have shown to be highly advantageous in the selective separation of proteins, metals and catalysts.41,42 For instance, a ABS system involving ammonium-based zwitterionic ILs (i.e. N,N,N-tripentyl-3sulfonyl-1-propaneammonium and polymers (i.e.

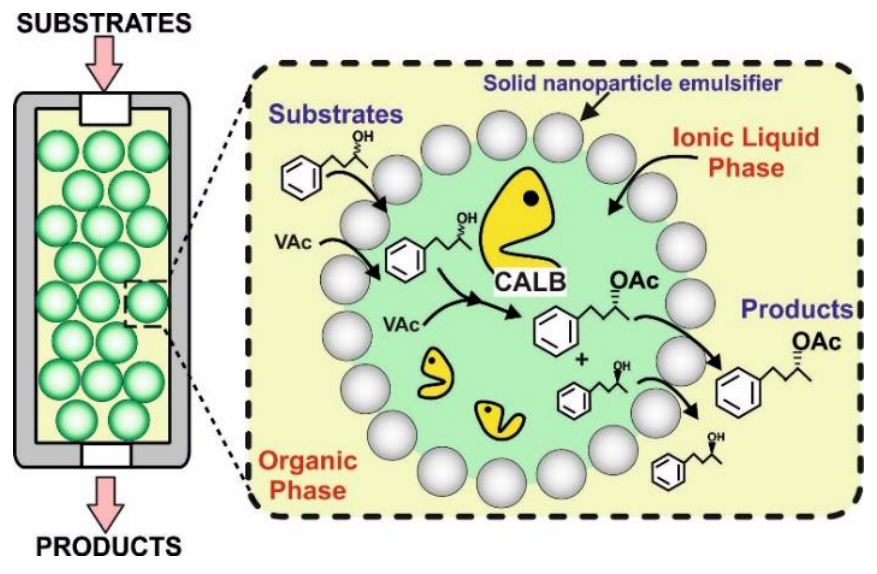

Fig. 2. Schematic illustration of an IL droplet-based continuous flow system in organic solvents, used for lipase-catalysed kinetic resolution of phenyl-2butanol. ${ }^{51}$

polyethyleneglycol, PEG) behaved as a homogeneous medium at $25^{\circ} \mathrm{C}$, being suitable for the homogeneous laccase-catalysed oxidation of 2,2'-azinobis3-ethylbenzathiazoline-6-sulfonic acid. An increase in temperature up to $40{ }^{\circ} \mathrm{C}$ induced changes in the phase behaviour, with the formation of two phases and the complete separation of the enzyme from the products in a single-step. The products were obtained in the PEG-rich phase (upper phase), whilst the IL-rich phase contained the enzyme (bottom phase), and could be reused for five cycles without any loss in activity. ${ }^{44}$

Two limitations can be perceived for some of these ABS systems. During the aqueous two-phase extraction, the recovery efficiency of ILs can be limited due to an inefficient partition of the ILs and/or catalyst between the two phases. Although, this may be improved by further exploration of the thermodynamic models, and by the re-design of ILs-based aqueous two-phase systems, it constitutes a limitation as can hamper a quantitative recovery of the catalyst upon continuous recycling. Furthermore, even if the separation of the ILaqueous phase is highly efficient, a further extraction of the products from the aqueous liquid phase is still required and can limit the greenness of the overall process.

In the search of more efficient multiphase L-L systems, the application to catalysis of Pickering emulsions, mitigating the use of synthetic surfactants and solvents, has been recently emerged as an interesting alternative. ${ }^{\mathbf{4 5}}$ Pickering emulsions are surfactant-free dispersions of two immiscible fluids that are kinetically stabilized by colloidal particles. ${ }^{46}$ These systems also provide an unprecedented opportunity for cascade reactions, providing the required isolation for mutually incompatible reagents of catalytic systems. ${ }^{\mathbf{4 7 , 4 8 , 4 9 , 5 0}}$

In the case of ILs, Yang and co-workers have demonstrated that IL-in-oil emulsion droplets can be generated through emulsification using immiscible nonpolar solvents as the oil phase (i.e. alkanes or aromatic hydrocarbons) and nanoparticles (i.e. dimethyl-dichlorosilane-modified silica nanospheres, 40$60 \mathrm{~nm}$ ) as solid emulsifiers. ${ }^{51}$ In this way ILs ranging from hydrophobic (i.e. $[\mathrm{Bmim}]\left[\mathrm{PF}_{6}\right]$ or $[\mathrm{Bmim}]\left[\mathrm{NTf}_{2}\right]$ ) to 
hydrophilic (i.e. $[\mathrm{Bmim}]\left[\mathrm{BF}_{4}\right]$ or $[\mathrm{Bmim}]\left[\mathrm{NO}_{3}\right]$ ) form the corresponding ILs-L Pickering emulsions, where each droplet can be considered as a microreactor with the IL enclosed in the interior and the emulsifier particles covering the surface of the droplets (Fig 2). ILs droplets remain intact without coalescing or aggregating and can be used as building blocks to develop a macroscale continuous flow system. A column packed with the stable droplets using a micron-sized pores filter installed at the bottom of the column allows developing continuous flow systems. The product dissolved in the oil phase continuously flows through the droplets, where the catalyst is encapsulated in the IL-phase (Fig. 2). Thus, for instance, a IL-droplets packed-bed reactor for the continuous catalytic enzymatic kinetic resolution of different alcohols and amines has been prepared by emulsification of CALB in the IL phase $\left([\mathrm{Bmim}]\left[\mathrm{PF}_{6}\right]\right)$. The system showed remarkable results, providing 1-phenylethyl alcohol with a high enantioselectivity (99\% ee) and a specific activity of $5.18 \mathrm{U} \mathrm{mg}^{-1}$, which constitutes a 25-fold enhancement when compared with the batch reaction $\left(0.21 \mathrm{U} \mathrm{mg}^{-1}\right)$ and significantly improves the enantioselection in batch $\left(16.5 \%\right.$ ee after $12 \mathrm{~h}$ in [Bmim] $\left.\left[\mathrm{PF}_{6}\right]\right)$. The system demonstrated an exceptional long-term stability with a running time, for the enantioselective trans-esterification of 1-phenylethyl alcohol, as long as 4000 hours without any leakage of the IL phase.

The generality of these ILs-L systems under flow conditions was demonstrated by applying this methodology to different catalytic reactions. Thus, the $\mathrm{Cu}^{\mathrm{I}}$-catalysed azidealkyne cycloaddition between benzyl azide and phenyl acetylene under flow conditions led to a productivity of 0.47 mol $\mathrm{mol}^{-1} \mathrm{~h}^{-1}$, which is 9-fold higher than the one obtained under batch conditions $\left(0.053 \mathrm{~mol} \mathrm{~mol}^{-1} \mathrm{~h}^{-1}\right)$. The same authors have also reported the encapsulation of $[\mathrm{Bmim}][\mathrm{Cl}]$ as catalyst within the $[\mathrm{Bmim}]\left[\mathrm{BF}_{4}\right]$ droplets, in a IL-based Pickering emulsion using $n$-octane, for the continuous-flow cyanosilylation reaction. ${ }^{52}$ A $2-3$ times enhancement in catalysis efficiency in comparison to the related batch reactions was reported. Moreover, this reaction system exhibited outstanding operational stability, as demonstrated by maintaining more than $95 \%$ conversions over 100 hours on stream.

In the search of more stable systems, the same authors developed, also based on Pickering emulsion droplets, liquidsolid hybrid systems through the preparation of a porous silica crust around the IL droplet, leading to encapsulate the IL-phase hosting free homogeneous molecular catalysts. This methodology brings together the easy recovery of the catalytic IL-phase and the use of advanced materials in conjunction with ILs. ${ }^{53}$ As a proof of concept, the enzymatic kinetic resolution of racemic alcohols, the $\mathrm{Cr}^{\mathrm{III}}$ (salen) complex-catalysed asymmetric ring opening of epoxides and the Pd-catalysed Tsuji-Trost allylic substitution were evaluated. The resulting hybrid catalyst-based continuous flow system exhibited enhancements in activity of 1.6 to 16 times relative to the homogeneous counterparts, as well as elevated stability (over $1500 \mathrm{~h}$ ) and enantioselectivities comparable to those obtained under homogeneous conditions.

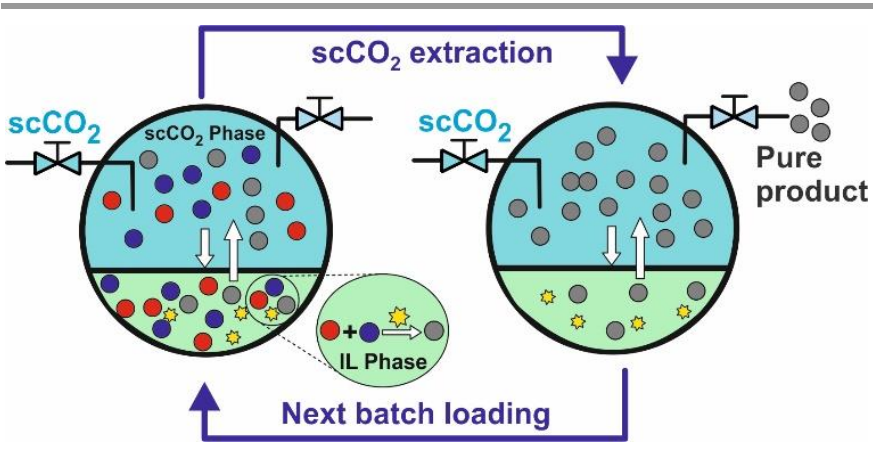

Fig. 3. General scheme for integrated reaction separation processes in $\mathrm{IL} / \mathrm{scCO}_{2}$ biphasic systems.

Although those systems represent a novel and practical methodology for the continuous separation and recycling of the catalytic IL-phase, they still suffer from the disadvantage, from a point of view of sustainability, of requiring the use of large amounts of organic solvent (i.e. n-octane) as the oil-phase and/or solvent.

In a similar context, it was also reported that water can be used instead of organic solvents for the formation of nano-sized aqueous IL-droplets, similar to those in w/o microemulsions. ${ }^{\mathbf{5 4}}$ Thus, for instance, a water-in-IL microemulsion ([Bmim] $\left[\mathrm{PF}_{6}\right] /$ Tween $\left.20 / \mathrm{H}_{2} \mathrm{O}\right)$ was successfully applied as reaction system to esterify phytosterols with fatty acids by Candida rugosa lipase (CRL). The lipase encapsulated in the microemulsion was used for $168 \mathrm{~h}$ without significant changes in the activity although, once again, an additional molecular solvent such as $n$-hexane had to be used as the extraction agent in order to isolate the product. ${ }^{55}$

Supercritical $\mathrm{CO}_{2}$ is recognized as an interesting alternative to organic solvents for carrying out green extractive multiphasic processes. ${ }^{56} \mathrm{ScCO}_{2}$ is highly soluble in the IL phase being also able to extract previously dissolved compounds in the IL-phase. Reversely the same IL cannot be detected in the $\mathrm{scCO}_{2}$ phase (Fig. 3). ${ }^{\mathbf{5 7}}$ This phase behaviour of ILs and $\mathrm{scCO}_{2}$ providing well defined biphasic systems, allows using $\mathrm{IL} / \mathrm{scCO}_{2}$ biphasic reaction media for catalysis opening new opportunities for integral green developments integrating the chemical transformation, the extraction/isolation of the products and the recovery of the catalytic IL-phase in a singleprocess. In such biphasic systems catalytic reactions benefit from the advantages of both homogeneous and heterogeneous catalysis, facilitating the recovery of the products and the catalytic IL-phase in both consecutive batch and continuous flow processes.

Many catalytic processes have been developed based on ILs/scCO 2 systems. ${ }^{\mathbf{5 8 , 5 9}}$ An illustrative example is the repetitive batch hydroboration of terminal and internal alkynes catalysed by $\mathrm{Ru}(\mathrm{CO}) \mathrm{Cl}(\mathrm{H})\left(\mathrm{PPh}_{3}\right)_{3}$ in biphasic $\mathrm{ILs} / \mathrm{scCO}_{2} .{ }^{60}$ Using $1 \mathrm{~mol}$ $\%$ of the catalyst in [EMPyrr][OTf] $/ \mathrm{ScCO}_{2}$ the hydroboration of phenylacetylene with pinacolborane takes place with high efficiency and the product is directly extracted in the $\mathrm{scCO}_{2}$ phase without the use of any organic solvent. The catalyst was active for 8 cycles cycles at a much lower reaction temperature 
than in standard protocols (i.e. 40 vs $100{ }^{\circ} \mathrm{C}$ ), being one of the most effective and recyclable systems based on ILs for the hydroboration of alkynes.

A novel switchable biphasic IL/scCO $\mathrm{SO}_{2}$ system coupling reaction and separation has been proposed for the efficient preparation of HMF from fructose. ${ }^{61}$ The miscibility of a mixture of an IL and an organic solvent (i.e. [Omim]Cl and acetone) was adjusted using $\mathrm{CO}_{2}$ as a "phase separation switch". When $\mathrm{CO}_{2}$ is introduced into the reactor, the fully miscible $[\mathrm{Omim}] \mathrm{Cl} /$ acetone mixture separates into two phases, with $\mathrm{scCO}_{2}$ being dissolved into both phases. Reactants and catalyst are mainly enriched in the IL phase and the produced HMF is continuously extracted into the organic solvent phase. This approach leads to $84 \%$ yield of HMF and the mass ratio of HMF between the organic solvent and the IL phase reaches a value of 1.3:1. Comparing to several commonly used systems including a biphasic system, this switchable biphasic reaction/separation coupling system was more efficient for HMF preparation. Such systems could provide additional applications for efficient reactions and separations in ILs. ${ }^{62}$

$\mathrm{ILs} / \mathrm{scCO}_{2}$ systems can also combine with additional individual catalytic platforms (metal- and organo-catalytic systems) for developing divergent synthesis. The simple isolation of the intermediate compound from the IL-phase by means of $\mathrm{scCO}_{2}$ allows successfully integrating two consecutive reactions using incompatible catalytic systems. This has been implemented in the divergent preparation of two alternative and interesting families of compounds ( $\alpha$-cyanoamines and cyanohydrin trimethylsilyl ethers) from the same starting material (allylic alcohol) without the need of any purification step for the intermediate aldehyde. ${ }^{\mathbf{6 3}}$

The equipment and energy costs regarding compression and decompression of $\mathrm{CO}_{2}$ should be considered when applying $\mathrm{IL} / \mathrm{scCO}_{2}$ technologies. This may be one of the reasons why, although a large number of (bio)catalytic processes have been reported at academic level, ${ }^{\mathbf{5 9 , 6 4 , 6 5 , 6 6}}$ there is still a lack of transfer from lab to real industrial applications.

In order to improve the separation of the products and the recovery of the active IL-phase, while reducing the amount of IL required, the immobilisation of the IL onto a support is envisioned as a suitable and practical alternative. ${ }^{\mathbf{2 9 , 6 7}}$ The immobilisation of the IL-phase can be performed by simple adsorption of the IL layer on the surface of a porous support (Supported Ionic Liquid Phases, SILPs) via wet impregnation or alternatively by encapsulation of the IL-phase during the synthesis of a porous material (ionogels). ${ }^{\mathbf{6 8 , 6 9}}$ Furthermore, SILP-based catalytic systems are exceptionally well suited for developing processes under continuous flow conditions. ${ }^{\mathbf{3 6}}$ SILPs have been applied for a variety of catalytic processes, in particular when the reagents are in the gas phase or are delivered and extracted by the $\mathrm{scCO}_{2}$ phase (i.e. hydroformylations, ${ }^{\mathbf{7 0 , 7 1 , 7 2 , 7 3}}$ hydrogenations, ${ }^{\mathbf{7 4 , 7 5 , 7 6 , 7 7}}$ methanol carbonylation, ${ }^{78} \quad$ low-temperature water-gas-shift, ${ }^{79}$ hydrosilylation, ${ }^{\mathbf{8 0}}$ etc). ${ }^{\mathbf{8 1 , 8 2}}$

$\mathrm{SILP} / \mathrm{scCO}_{2}$ systems also allow the development of fully green biocatalytic processes in non-aqueous environments,

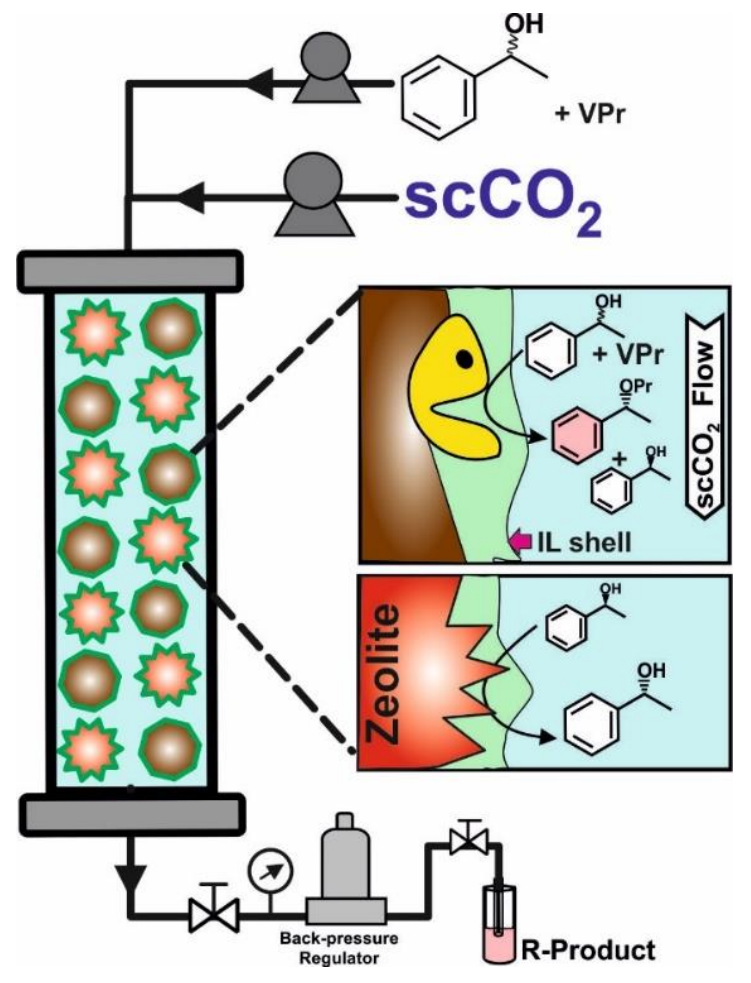

Fig. 4. Schematic representation of a SILP / $\mathrm{ScCO}_{2}$ biphasic system used for the dynamic kinetic resolution (DKR) of rac-1-phenylethanol carried out by using vinyl proprionate (VPr) as acyl donor, and the combined action of an immobilized lipase and an acidic zeolite as catalysts. ${ }^{85}$

where the biotransformations occur in the supported IL-phase (catalytic phase), while substrates and products remain largely in the supercritical phase (extractive phase, Fig. 4). These systems brings together, in an individual process, the classical advantages of $\mathrm{scCO}_{2}$ to extract, ${ }^{\mathbf{8 3}}$ dissolve and transport chemicals and the capacity of ILs to stabilize enzymes. ${ }^{\mathbf{8 4}}$ Furthermore, the SILP/scCO $\mathrm{SO}_{2}$ combination can be straightforwardly implemented for developing biocatalytic cascades involving multi-catalytic chemo-enzymatic systems. Thus, a green and clean non-aqueous continuous process has been reported, based on the combination in a single reactor two SILP-based systems. One of them (Novozym $\left.435 /[\mathrm{Btma}]\left[\mathrm{NTf}_{2}\right]\right)$ provides the biocatalytic kinetic resolution of 1-phenyl-ethanol, while the second incorporates a zeolite (H-USY-CBV400/[Btma][ $\left.\mathrm{NTf}_{2}\right]$ ) as an acid racemising catalyst. The $R$-phenyl-ethyl propionate was obtained with good yields (up to $98.0 \%$ ) with excellent enantioselectivity (up to $97.3 \%$ ee) and without any activity loss for 14 days of operation at $50{ }^{\circ} \mathrm{C}$ and 100 bar. $^{85}$

These systems provide a simple and highly stable solution for the application of ILs enabling a simple recovery of the products and the continuous reuse of the catalytic IL-phase. Additionally, if the reaction product does not require any further purification, the approach enhances the economic benefit of the process, because the system transforms pure substrates into pure products without waste generation. 
The advantages of SILP-based systems have led to the development of processes on an industrial scale. In this regard, an IL containing the chlorocuprate anion and impregnated on high surface area porous solid supports has been commercialised as HycaPure-Hg for the effective removal of mercury vapour from natural gas streams in a Petronas gas processing plant in Malaysia. ${ }^{\mathbf{8 6}}$ After three years of continuous operation, the mercury concentration from the plant outlet remained low, meeting the target specifications. This represents a remarkable success of transferring laboratory chemistry to full scale plant operation. This SILP is now commercialised via a marketing licensing agreement between Petronas and Clariant.

Evonik demonstrated in a pilot plant that a SILP-based catalyst could work reliably for around 2000 hours. Evonik's system involved an ionic liquid consisting of imidazolium cations and amine-based anions, and a homogeneous catalyst. The simulation of commercial hydroformylation integrating the SILP-based catalyst reduced $\mathrm{CO}_{2}$ emissions by a two percent as compared to the Evonik's process with a homogeneous catalyst, which already was quite efficient. ${ }^{87}$

SILPs are also involved in a novel technology to produce ethylene glycol (EG) and dimethyl carbonate (DMC) via alcoholysis of cyclic ethylene carbonate (EC). A SILP was used as catalyst in a bed reactor fed with $\mathrm{CO}_{2}$ and ethyl oxide (EO) in a $2: 1$ flow ratio to obtain the EC product in nearly $99.5 \%$, which was transferred to the next column for alcoholysis. ${ }^{\mathbf{8}}$ Based on a $1000 \mathrm{~h}$ successful continuous test, the World's first plant for production of dimethyl carbonate/ethylene glycol (DMC/EG) from $\mathrm{CO}_{2}$ catalysed by SILPs was built in China, with an output of 33,000 t/a. The quality of DMC reached the battery level standard (purity $\geq$ $99.99 \%$ ), and that of EG was superior to the national standard (purity $\geq 99.93 \%$ ). This technology will reduce about 0.5 tons of $\mathrm{CO}_{2}$ per ton of product, saving energy consumption by $50 \%$

SILPs, however, have the limitation, especially for continuous processes, of the potential lixiviation of the IL or the catalyst in the IL-phase by abrasion and dissolution. The covalent functionalization of solid surfaces with IL-like moieties (Supported Ionic Liquid-Like Phases, SILLPs) provides a practical and simple solution for avoiding the lixiviation of the IL-phase. Both organic and inorganic

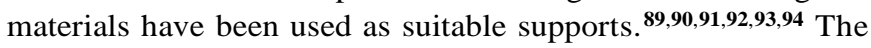
IL-like units provide the modified support with some of the main features of molecular ILs (stability, tuneable polarity, nanostructure, etc.), ${ }^{\mathbf{9 5}}$ while the support itself is an additional design vector to optimize the macroscopic and process properties of SILLPs. The topology and porosity of the support can be tailored by varying the synthetic methodology and the connectivity, size, and geometry of the building blocks by a bottom-up approach, leading ideally to a perfect control of the size and the shape of the environment inside the cavities or on the surface of the material, enhancing the control of the chemo physical properties of the resulting materials. ${ }^{\mathbf{9 6 , 9 7}}$ Hence, the internal and external surfaces of SILLPs display similar features than bulk ILs but these materials simplify product isolation and recycling of the catalyst-IL-phase as well as eliminate (eco)toxicological concerns and their use reduces the

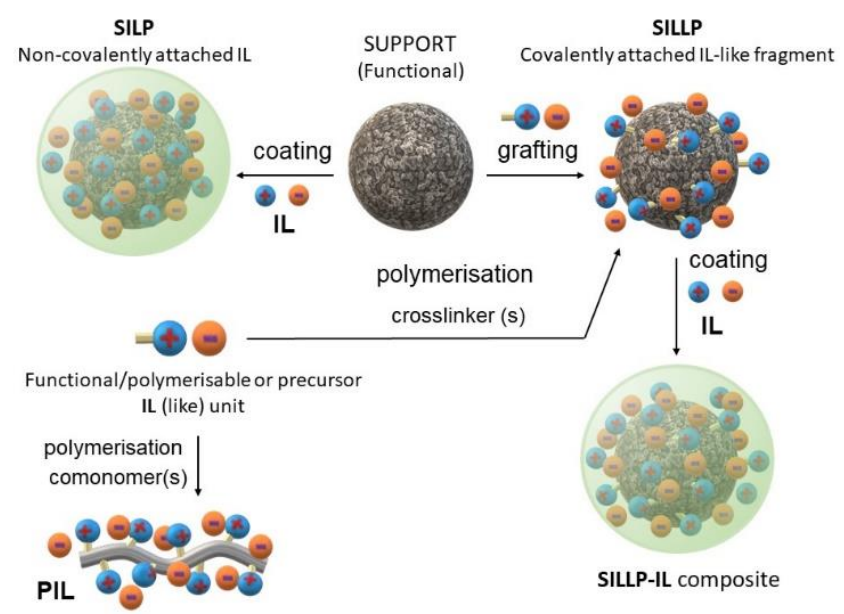

Fig. 5. General approaches for the preparation of materials based on ILs. Adapted from ref. 96 with permission from the Royal Society of Chemistry.

amount of IL needed, which can often be an important cost factor for the process. In a similar way to liquid IL-phases, they can also be used to fine-tune the catalyst performance assisting the activation of the catalyst, generating novel catalytic species, improving catalyst stability and influencing the selectivity. ${ }^{\mathbf{9 8}}$

SILLPs can be prepared through post-funcionalization of an already preformed support, introducing the IL-like units by grafting methodologies, ${ }^{99}$ or by polymerization of a monomer containing IL-like moieties (Fig. 5). ${ }^{\mathbf{9 6}}$ The simplest approach is the modification of a support with the appropriate properties and functionality. Amines, phosphines, imidazoles and other heterocycles can react with alkylating groups in the support to afford IL-like fragments. ${ }^{\mathbf{9 6 , 9 8 , 1 0 0}}$ Other groups of the support, like $-\mathrm{NH}_{2},-\mathrm{CH}_{2} \mathrm{SH},-\mathrm{CO}_{2} \mathrm{H}$, etc. have been used for the introduction of IL-like units and the creation of imidazolium rings from polymer-bound amines has been reported. ${ }^{101}$ For inorganic supports, free hydroxyl groups on the surface are used for the attachment, employing sol-gel approaches and alkoxyorganosilyl derivatives containing the desired IL-like functionality or its precursor. ${ }^{6892,93,94}$ The presence on the surface of a solid of IL-like fragments can be used to introduce an additional IL layer reducing its potential leaching. ${ }^{102}$ Task specific ILs can also be prepared in combination with a support. ${ }^{\mathbf{1 0 3 , 1 0 4}} \mathrm{A}$ large diversity of SILLPs, varying the cation or the anion, as well as the nature and loading of the support, have been characterized, including their thermal stability and polarity, which was dependent on the polarity induced by structural changes in the IL-like moieties. Thus, such materials might be regarded as "solid ionic solvents" or as nanostructured materials based on IL-like units with microenvironments of tunable polarity, able to immobilize and stabilize different catalytic species. ${ }^{36,98}$

One main advantage of SILLPs is that the covalent attachment of the IL-phase to the support facilitates solventfree reactions in the absence of any interference from leaching. This is exemplified in their application for the continuous-flow cyanosilylation of carbonyl compounds using trimethylsilyl- 


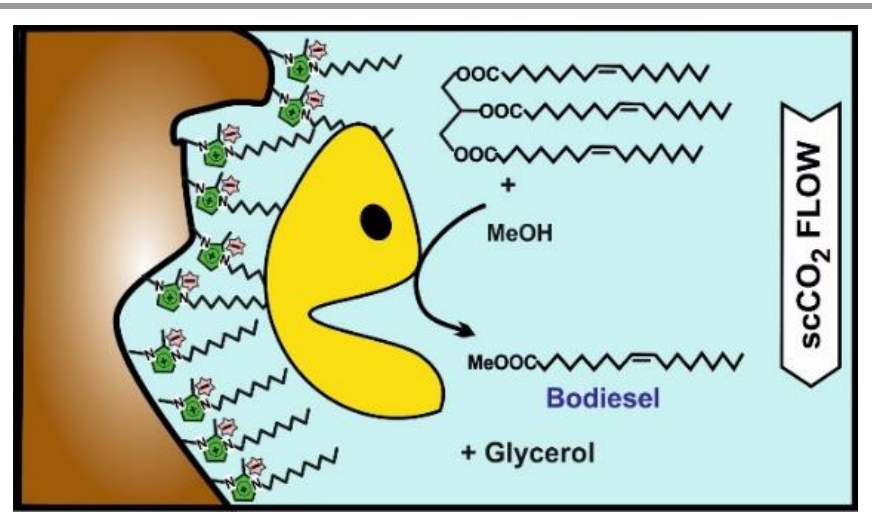

Fig. 6. Schematic representation of CALB-SILLPs catalysed biodiesel synthesis under $\mathrm{ScCO}_{2}$ flow conditions. ${ }^{109}$

cyanide. ${ }^{63}$ Pure products were obtained, not requiring further purification steps, with productivities up to $45.1 \mathrm{~g} \mathrm{~g}^{-1}$ SILLP $\mathrm{h}^{-}$ 1 , and without any indication of decrease in activity / selectivity after running continuously for more than two days. Similar approaches have been used for other solvent-free reactions under continuous flow conditions such as the Henry nitroaldol reaction using a monolithic mini-reactor, ${ }^{105}$ or the continuous cycloaddition of $\mathrm{CO}_{2}$ to epoxides displaying a stable efficiency for more than 130 h. ${ }^{106}$

Bioreactors can also be prepared from styrenedivinylbenzene polymeric monoliths containing imidazolium units. In these materials, a covalent IL-coating of the solid support surface with $c a$. 55 to $40 \%$ of the weight corresponding to the IL moiety introduced. ${ }^{107}$ This IL-phase is able to adsorb and stabilize Candida antarctica lipase B, leading to highly active and stable immobilized biocatalysts during continuous operation using $\mathrm{scCO}_{2}$ (i.e. for the synthesis of citronellyl propionate in $\mathrm{scCO}_{2}$ at 100 bar and $40-100^{\circ} \mathrm{C}$ ).

In another example, a variety of nanostructured supports, based on different 1-decyl-2-methyl-imidazolium cations covalently attached onto a polystyrene-divinylbenzene porous matrix, were used as carriers to immobilize CALB. The presence of the IL-like moieties not only led to more active and stable enzymatic catalysts but allowed their use under continuous flow conditions. ${ }^{\mathbf{1 0 8}}$ CALB-SILLPs have been successfully used for the synthesis of biodiesel (methyl oleate) by methanolysis of triolein under a $\mathrm{scCO}_{2}$ flow (180 bar, $45^{\circ} \mathrm{C}$, see Fig. 6) obtaining excellent biodiesel yields (up to 95\%) and high operational stability ( $85 \%$ biodiesel yield after 45 cycles of 8-4h). ${ }^{109}$

In the same context, the mixing of these CALB-SILLPs derivatives with acid zeolite particles (i.e. CP811E-150) provided access to an excellent one-pot mini-flow-bioreactor to perform the continuous DKR of rac-1-phenylethanol with vinyl propionate in $\mathrm{scCO}_{2}$ with yields for the desired product of up to 92\% and with ee $>99.9 \% .^{110}$ These IL-based materials also allow the development of multistep multicatalytic systems combining chemical and biocatalytic steps in a single telescopic process, where the product of one step is used without any further purification as the reactant for the consecutive transformation (i.e. the multistep synthesis of aminoalcohol ${ }^{\mathbf{1 1 1}}$ or chiral cyanohydrins ${ }^{\mathbf{1 1 2}}$ ) allowing multistep reaction to be performed under flow and avoiding deactivation/incompatibility issues found in related single-pot batch syntheses.

Thus, it seems clear that the immobilisation of a IL-phase onto a support or the development of IL-based materials constitutes a very effective methodology for the recovery and reuse of the IL-phase, integrating product separation, and leading to further process advantages like the application of flow conditions, catalysis tunability in terms of activity and selectivity, long term stability, simpler scale-up, etc.

\section{Metal Nanoparticles in ILs}

Soluble and stable transition metal nanoparticles (MNPs) can be easily prepared in ILs by several methods including simple reduction of cations, decomposition of organometallic complexes in the formal zero oxidation state, etc., giving access to MNPs having different sizes, shapes and properties as a function of the nature of the involved ILs. ${ }^{113,114,115}$

Catalytic reactions performed by MNPs in ILs are usually carried out under two- or three-phase conditions, in particular when gases are involved. For example, the excellent suitability of ILs, under those conditions, for the MNPs-catalysed hydrogenation of substituted olefins and aromatic compounds has been widely reported (Fig. 7). ${ }^{116,117,118}$

It should be noted that ILs act simultaneously as both solvent and stabiliser for MNPs and that only a simple thin film of the IL around the MNP is required in order to tune the selectivity and avoid its collapse and loss of activity, which can be a key issue when MNPs separation is dealt with after their use as catalysts. ${ }^{119}$ According to this, the use of Supported Ionic Liquid Phases (SILPs) and related advanced materials (SILLPs, Polymeric Ionic Liquids: PILs, etc.) represents a simple and convenient method to improve the stability of catalytic MNPs and facilitate their preparation, separation and reuse. In such systems, the direct contact of the colloidal NPs with the IL-phase restricts direct interactions between particles, controlling NP growth and aggregation. Additionally, both the nature of the support, as mentioned before, and the physicochemical properties of the IL-phase can be used for the fine tuning of MNPs properties. For instance, the influence on the synthesis and stabilization of AuNPs of the structure and morphology of SILLPs prepared by grafting a variety of imidazoles onto commercial Merrifield-type resins was studied in detail. ${ }^{120}$ Variables considered included the loading of imidazolium units, the resin morphology (gel type vs. macroporous), the alkyl substitution at the imidazolium moiety (methyl, butyl or decyl) and the counteranion present $\left(\mathrm{Cl}^{-}\right.$or $\mathrm{NTf}_{2}{ }^{-}$). Both the microgel / macroporous structure of the polymer and the alkyl-substitution of the imidazole were used to tune the AuNPs size distribution in the range of 2-25 nm.

These systems were also used to catalyse synthetic transformations employing aqueous or green organic solvents. Thus, these AuNPs-SILLPs were used as efficient catalysts for the oxidation of phenyl ethanol in water using $\mathrm{H}_{2} \mathrm{O}_{2}$ as the oxidant and under microwave irradiation. ${ }^{\mathbf{1 2 1}, 122}$ The fine-tuning of the support and the hydrophobic / hydrophilic balance were 


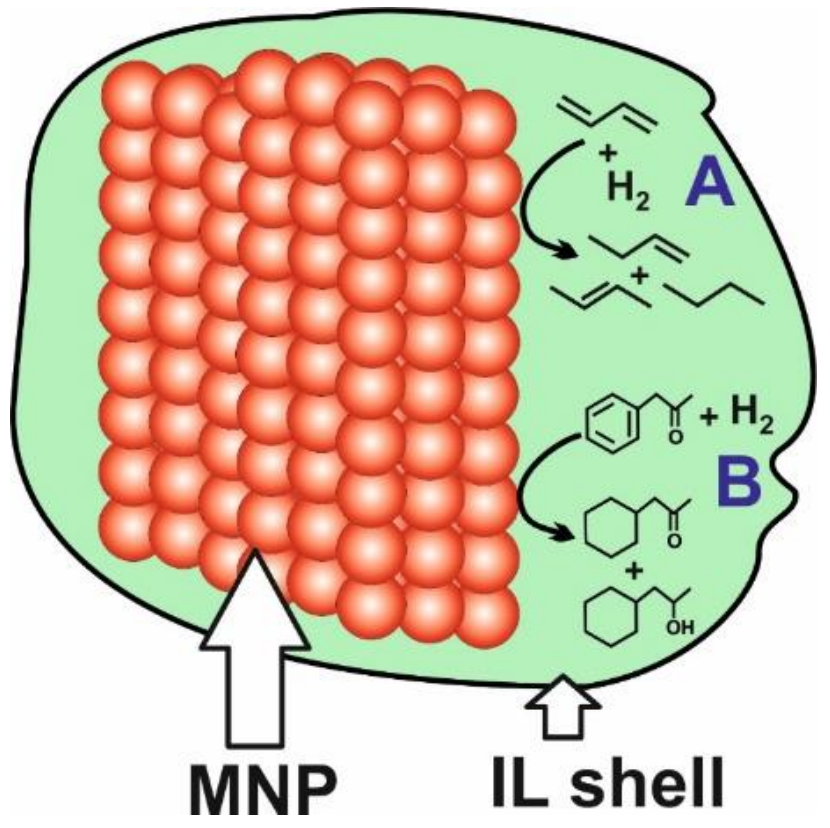

Fig. 7. Schematic representation of hydrogenation reactions catalysed by ILcoated metal nanoparticles (MNPs-IL). A Hydrogenation of olefins by PtNPs in $[\mathrm{Bmim}]\left[\mathrm{BF}_{4}\right]{ }^{117} \mathrm{~B}$, Hydrogenation of benzylmethylketone catalysed by IrNPS coated by $[\mathrm{Bmim}]\left[\mathrm{PF}_{6}\right]{ }^{118}$.

employed to enable an efficient diffusion of the substrate from the polar solvent to the active catalytic sites. Besides, the IL units on the support favour an efficient absorption of microwave irradiation optimizing energy factors.

Similar systems based on PdNPs of very small size $(<2$ $\mathrm{nm}$ ) were shown to catalyse the selective hydrogenation of $p$ chloronitrobenzene to $p$-chloroaniline. ${ }^{\mathbf{1 2 3}} \mathrm{N}$-butyl substitution at the IL-like moieties provided an almost total selectivity at full conversion. Since the average size of the PdNPs was the same in all the catalysts, this suggested that chemoselectivity depended on the polarity of the environment provided by the IL-like fragments, which directly affects the electronic and surface properties of the hosted PdNPs. Similar supported PdNPs have also been used as catalysts for a variety of C-C coupling reactions. ${ }^{\mathbf{1 2 4}}$ The IL-like moieties stabilize the NPs and simultaneously reduce significantly their leaching through a release and catch mechanism facilitating separation processes. ${ }^{125}$ The separation, recovery and reuse of these MNPs-SILLPs can be further improved by their use in continuous flow processes. Thus, for instance, RuNPs-SILPs integrating acid and metal catalytic sites onto a single-support have been reported for the continuous flow hydrodeoxygenation of eucalyptol, ${ }^{\mathbf{1 2 6}}$ while PdNPs-SILLPs have been used for $\mathrm{C}-\mathrm{C}$ bond formation using $\mathrm{scEtOH}$ as the solvent. ${ }^{125}$

Furthermore, immobilised IL-phases provide an opportunity to reduce the amount of IL required in the formation of stable MNPs-ILs systems, but also for the introduction of additional orthogonal functionalities near the MNPs. The potential of this approach for designing and generating multifunctional catalytic systems with tailor-made reactivity for challenging catalytic transformations is exemplified with the $\mathrm{Fe}_{25} \mathrm{Ru}_{75} \mathrm{NPs}-\mathrm{SILP}+\mathrm{IL}-\mathrm{SO}_{3} \mathrm{H}$ system reported for the selective hydrodeoxygenation of aromatic ketones. ${ }^{127}$ In the case of the Heck reaction, the use of a polymeric cocktail containing both a basic SILLP and PdNPsSILLPs, allowed to prepare a packed bed reactor allowing a very efficient continuous-flow process with $\mathrm{scCO}_{2}$ as the solvent. This process fully integrated reaction and separation and afforded directly the pure target product at the outlet of the reactor. ${ }^{\mathbf{1 2 8}}$ The same reactor could be reused efficiently not only for successive Heck reactions but also for alternative C-C coupling processes, which represents a significant improvement in terms of green chemical processes.

\section{Membrane reactors based in IL technology}

Membrane technologies afford a series of advantages regarding the integration of reaction/separation systems. Namely: i) reaction improvements: they allow shifting in the desired direction equilibrium-limited reactions by continuous removal of one of the products (i.e. $\mathrm{H}_{2} \mathrm{O}$ or $\mathrm{MeOH}$ ), ii) energy savings: they allow separation at low temperature with the associated energetic savings, also enabling the separation and or purification of thermally unstable or non-volatile compounds, iii) selectivity enhancement: side reactions can be suppressed at a large extent by the removal of reactive intermediates and/or products, iv) catalyst lifetimes: by enabling a simple catalyst separation and recycling. Thus, the combination of catalytic IL-phases and membranes can be used not only to separate the product, but also to recover the catalytic IL-phase while increasing the chemical efficiency of reaction.

Fig. 8 illustrates how both the reaction and the separation of the products can be integrated in a single process for the enzymatic synthesis of flavour esters (i.e. ethyl acetate or isoamyl acetate) through esterification in ILs. ${ }^{32,129}$ The esterification of acetic acid and isoamyl alcohol was performed in a stirred-tank reactor containing [Bmim][PF 6$]$ using immobilized CALB as the catalyst. The coupling of two membrane units to the reactor permitted sequentially removing both water and the product (isoamyl acetate) shifting in this way the equilibrium to the formation of the ester by a double pervaporation process. By using one hydrophilic and one hydrophobic membrane, the system worked under continuous operation for 72 hours without any loss of enzyme activity.

Beyond the application of membranes to separate and recover the IL-phases, ILs themselves can be exploited to develop advanced membrane systems serving as separators between the feeding and the receiving phase. In such systems the amount of IL-phase needed for a given process is minimised and its recovery and reusability is favoured. In this context, different types of IL-membranes have been developed including supported ionic liquid membranes (SILMs), ILs composite polymer membranes (ILPMs), ionic liquids composite mixed matrix membranes (ILMMMs), poly(ionic liquid)s membranes (PILMs), ionic liquid gel membranes (ILGMs), and ionic liquid membrane contactors (ILMCs). 


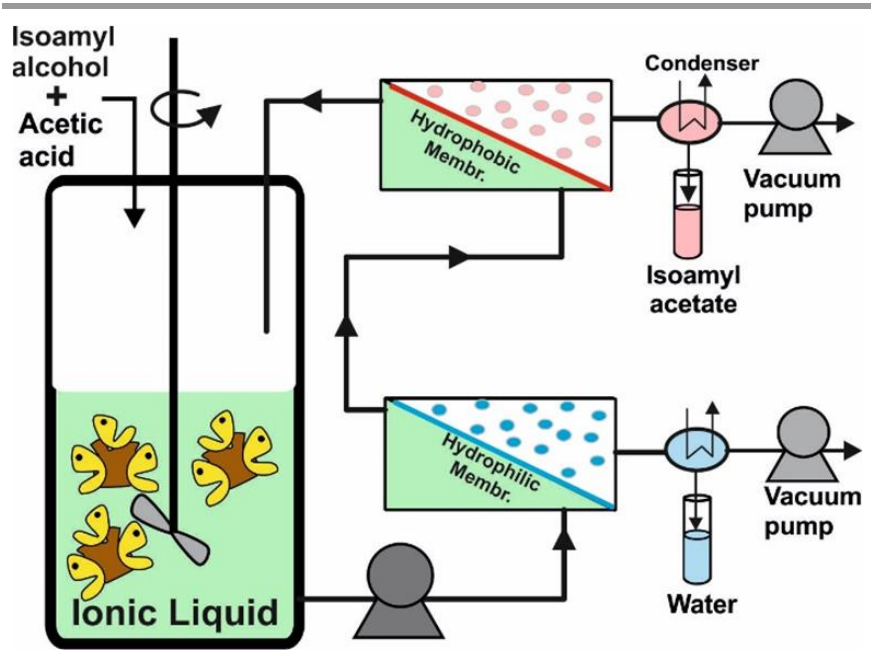

Fig. 8 Immobilized lipase-catalysed isoamyl acetate synthesis in [Bmim] $\left[\mathrm{PF}_{6}\right]$ using a stirred tank reactor coupled to pervaporation units for products separation. ${ }^{32}$

Their peculiarities and applications have been discussed and compared in dedicated reviews. ${ }^{\mathbf{1 3 0 , 1 3 1 , 1 3 2}}$ In brief, SILMs are systems where an IL is held by capillary forces in the pores of a supporting material. Both polymeric and inorganic membranes can act as such supports. Alternatively, ILs can be entrapped in a material to form a thin and stable quasisolidified film to afford IL-polymer membranes (ILPMs). Membranes obtained by polymerisation of the corresponding IL-based monomers or by chemical modification of the polymeric precursor with IL-related fragments lead to polymerized ionic liquids (PILs) that can achieve a high density of functional groups and provide materials with good mechanical stability appropriate for their use in membranes (PILMs and other systems). The multiplicity of potential approaches to incorporate ILs in the field of advanced materials offers unlimited synthetic possibilities in this area.

Most reported membranes containing IL or IL-like phases have been applied for the separation of gases (i.e. $\mathrm{H}_{2}, \mathrm{CO}_{2}$, $\mathrm{CH}_{4}$, etc.), ${ }^{133}$ but many of them also have a great potential for the integration of reaction/separation processes, especially for transformations involving gases. Fig. 9 illustrates the use of an PIL-membrane containing $\mathrm{Zn}\left[\mathrm{NTf}_{2}\right]_{2}$ and carbonic anhydrase (CA) to facilitate simultaneously the selective adsorption of $\mathrm{CO}_{2}$, its catalytic conversion into $\mathrm{HCO}_{3}{ }^{-}$, and the selective release of the transformation product $\left(\mathrm{HCO}_{3}{ }^{-}\right)$into a MEA (monoethanolamine) or MDEA (N-methyldiethanolamine) aqueous solutionf. ${ }^{\mathbf{1 3 4}}$ The combined effect of the IL-phase in the membrane and the presence of $\mathrm{CA}$ led to a $c a$. two-fold enhancement in the absorption rate $\mathrm{CO}_{2}$ in comparison with a system without enzyme or active IL-layer on the membrane surface. ${ }^{135}$

ILs membranes were prepared using a photo-grafting process with imidazolium-based ionic liquid monomers as modifying agent and microPES $®$ as support membrane, where

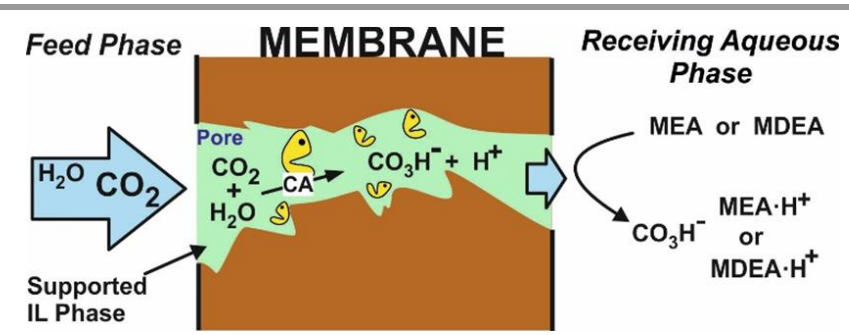

Fig. 9 Schematic representation of a PIL-modified hydrophobic membrane containing $\mathrm{Zn}\left[\mathrm{NTf}_{2}\right]_{2}$ and immobilized CA for $\mathrm{CO}_{2}$ conversion at low feed gas pressure (1.3 bar) with a feed gas composition of $15 \% \mathrm{CO}_{2}$ in $\mathrm{N}_{2}{ }^{134}$

the ILs serves as a stabilizer and immobilizer for the PdNPs catalytic species. ${ }^{\mathbf{1 3 6}}$ Their application for the Suzuki-Miyaura cross-coupling reaction in a flow-through arrangement using an Amicon cell, rendered a simple system integrating reaction and separation. The desired product was directly and continuously obtained in the permeate once the reaction started. No separation of the catalyst from the product was required. Furthermore, the high efficiency of the catalytic membrane favoured a better chemoselectivity towards the kinetically favoured product, achieving full conversion under mild conditions together with a significant improvement in the performance ( 2000 times faster in terms of reaction time for total conversion) as compared to the use of colloidal PdNPs under batch conditions.

A polymeric IL membrane obtained by graft copolymerization of an acidic IL and PVA illustrates the potential of the IL-phase to integrate reaction and separation in the esterification reaction between ethanol and acetic acid in a pervaporation catalytic membrane reactor (PVCMR). ${ }^{137}$ In the bilayer membrane, the catalytic activity is given by the presence of the acidic sites of the task-specific IL-phase, while the PVA provided good permeability. The conversion between acetic acid and ethanol reached $93 \%$ after $12 \mathrm{~h}$ at $75^{\circ} \mathrm{C}$ representing a $\mathrm{ca} .19 \%$ enhancement in comparison with results achieved for the equilibrium conversion in a batch reactor under the same conditions.

Membrane technology is also one of the best methods for the separation of oil from oil-water mixtures. ${ }^{\mathbf{1 3 8}}$ In this context, IL-membranes have been developed through different approaches, including chemical modification, ${ }^{\mathbf{1 3 9}}$ solvothermal synthesis, ${ }^{\mathbf{1 4 0}}$ electrospun materials, ${ }^{\mathbf{1 4 1}}$ etc. Indeed, porous monolithic advanced functional materials based on SILLPs have been used for the preparation of oleophilic and hydrophobic cylindrical membranes and successfully tested as membranes for oil/water separation. ${ }^{\mathbf{1 4 2}}$ The macroscopic properties of these porous monolithic tubular membranes could be tailored through the proper selection of the monomeric composition and by postmodification with different IL-like fragments, allowing the efficient separation of water/hexanes or water/2-Me-THF mixtures. Besides, this system enabled the separation of the product resulting from the biphasic reaction between a solution of furfural and acetone in 2-Me-THF and 


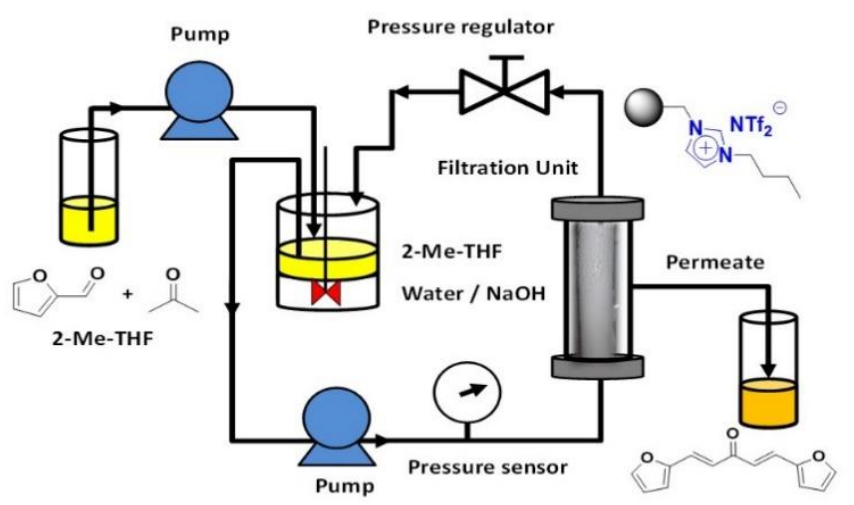

Fig. 10 Experimental set-up for the integrated continuous synthesis and separation of a difuryl compound based on a IL-based monolithic-membrane. ${ }^{135}$

aqueous $\mathrm{NaOH}$ as the catalytic phase (Fig. 10). The corresponding difuryl aldol product was obtained in a continuous flow process integrating the continuous reaction and the simultaneous separation of the product, with a yield > $90 \%$, a mean permeate mass flow of $208 \mathrm{~g} \mathrm{~h}^{-1} \mathrm{~m}^{-3}$ and the continuous full recovery of the aqueous catalytic phase in a single process.

\section{Microfluidic reactors based in IL technology}

Microfluidic reaction technologies represent very promising approaches for chemical and biochemical processes, being possible the development of chemo-enzymatic multistage designs based on microfluidics for the continuous production of many fine chemicals like antibiotics, antitumor drugs, drug delivery agents, and more. ${ }^{\mathbf{1 4 3 , 1 4 4}}$ The dimensions of microfluidic devices allow highly efficient mass transfer through the efficient mixing of the different components and rapid and controllable heat exchange due to the higher surfaceto-volume ratio, resulting in better reaction yields and reaction rates than for traditional reactors, with low energy use. This is essential, for instance in controlling exothermic reactions and avoiding runaways. ${ }^{\mathbf{1 4 5}}$ Furthermore, it is possible to have an easy separation of reaction products with less environmental impact as compared to macroscale, traditional reactors. ${ }^{\mathbf{1 4 6}}$

The combination of ILs and microreactor technology can enhance the efficient usage of ILs reducing IL consumption, which is hardly achievable in large-scale reactors, and this opens new opportunities for process intensification. Furthermore, the control of the fluidodynamic regime in multiphasic systems (G-L or L-L) can be used to manage and improve reaction selectivity and yields. This can be achieved, for instance, by controlling bubble and droplet sizes in segmented flows. The productivity of these systems can be enhanced through reactor design and the scale up can be approached via different methodologies, one of the most simple being the numbering-up of the microreactors. ${ }^{147}$ This is illustrated in the case reported by Zhao et al. where microreactor technology remarkably enhanced the synthesis rate of cyclic carbonate. ${ }^{\mathbf{1 4 8}} \mathrm{A}$ hydroxyl-functionalized IL (i.e. HETBAB) was used as the catalyst reducing the residence time from several hours to about $10 \mathrm{~s}$. Turnover frequency (TOF) values ranged from 3000 to $14000 \mathrm{~h}^{-1}$, while were in the order of $60 \mathrm{~h}^{-1}$ in the conventional stirred reactor. The space time yields (STYs) ranged from 650 to $4500 \mathrm{~g}_{\text {prod. }}\left(\mathrm{g}_{\text {cat. }} \mathrm{h}\right)^{-1}$, which was much larger than the value in the conventional case ( $c a .19$ g prod. $\left.\left(\mathrm{g}_{\text {cat. }} \mathrm{h}\right)^{-1}\right)$. Although the mass transfer performance of $\mathrm{CO}_{2}$ and propylene oxide (PO) was improved in the microreactor as compared to conventional reactors, the reaction was still affected by gas-liquid mass transfer. In a fully different example, palladium-catalysed multiphase carbonylation reactions in $[\mathrm{Bmim}] \mathrm{PF}_{6}$ using a microflow system showed superior selectivity and yields than the conventional batch system in carbonylative Sonogashira coupling and amidation reactions of aryl iodides. Since CO exhibits low solubility in highly viscous ILs, the reactions were controlled by the efficient diffusion of CO. The liquid-gas segmented Taylor flow enhanced the actual surface-to-area ratio leading to an excellent selectivity and high yields at relatively lower $\mathrm{CO}$ pressures. ${ }^{\mathbf{1 4 9}}$ Similar reductions in reaction times and productivity increase have been reported for other (bio)catalytic systems using microreactor technologies. ${ }^{\mathbf{1 5 0 , 1 5 1 , 1 5 2}}$

However, microreactor systems can also be used to minimize the use of both ILs and the involved catalysts significantly facilitating separation processes for the participating species and phases. ${ }^{\mathbf{1 5 3}}$ Thus, for instance, butyl cinnamate can be obtained by a Mizoroki-Heck reaction in a low viscosity IL $[\mathrm{Bmim}]\left[\mathrm{NTF}_{2}\right]$ containing the Pd catalyst. The reaction takes place by mixing this catalytic phase with a second fluid containing the reactants. ${ }^{\mathbf{1 5 4}}$ After reaction, the ILphase containing the $\mathrm{Pd}$ catalyst could be continuously recycled by washing out the ammonium salt byproduct with a $\mathrm{NaOH}$ solution and extracting out the product with hexane. Although this approach has the drawback of needing an organic solvent for the separation of the product, the separation of the active catalyst was simple and no decrease in product yield (90-99\%) was observed for several runs. This approach can also be easily applied for other chemical transformations as has been illustrated in the case of Suzuki or Sonogashira. ${ }^{155}$ hydrogenation, ${ }^{156}$ or hydroxylation reactions. ${ }^{157,158}$

The efficiency of biocatalytic reactions can be also improved using microfluidic reaction devices, with the possibility of enhancing the control of the reaction, minimizing the contamination of the products by the enzyme, or enabling the recovery and reuse of the biocatalyst. ${ }^{159}$ Although different systems have been studied to immobilize enzymes (i.e. polymers, glass or silica), the most popular biocatalytic microreactors are based on surface-immobilized enzymes, where enzymes are linked to the surface of a pre-constituted microreactor through the previous activation of the inner channels of a capillary reactor and exposed to the flow of reagents. Alternatively, porous beads, previously 


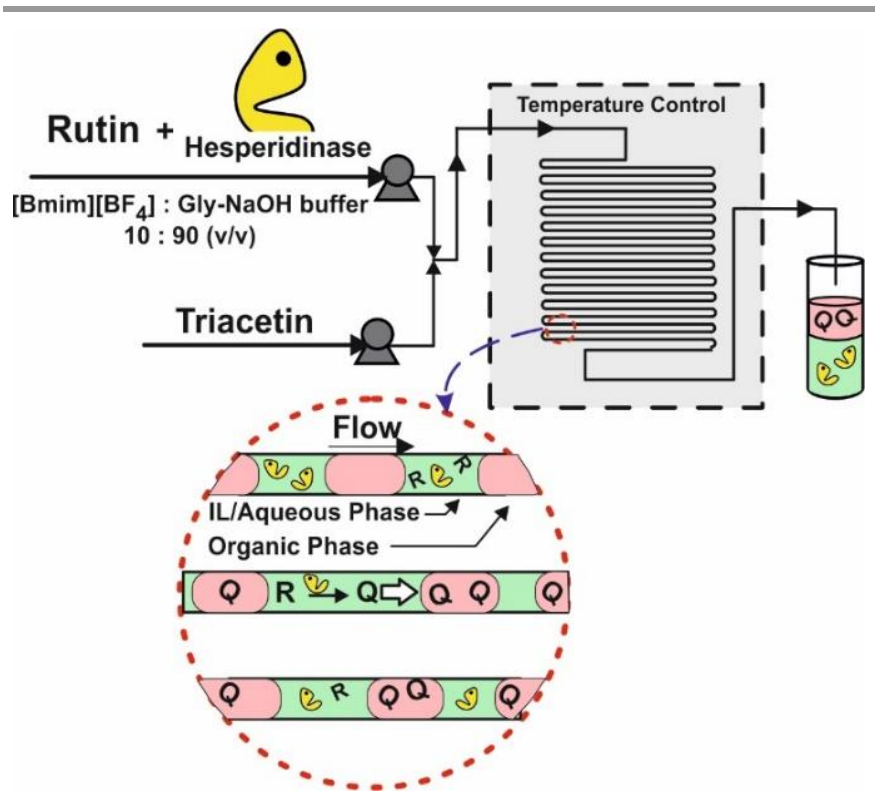

Fig. 11. Schematic representation of the microreactor and the segmented flow patterns in the microchannels for the integrated biocatalytic synthesis and separation of quercetin (Q) by the hespirinidase-catalysed hydrolysis of rutin (R). The catalytic phase (green) was a $10 \% \mathrm{v} / \mathrm{v}\left[\mathrm{Bmim}^{2}\left[\mathrm{BF}_{4}\right]\right.$ solution in glycine/ $\mathrm{NaOH}$ buffer ( $\mathrm{pH} 9$ ), and the extraction phase (rose) was glycerol triacetate. ${ }^{164}$

functionalized with enzymes, can be used to fill the channels of the microfluidic device. The combination of miniaturized technologies and microfluidics allowed the coupling of scaleand time-dependent phenomena for bioprocess intensification. However, coupling microreactors and biocatalysis is highly complex, requiring an integrated approach addressing biocatalyst features, reaction kinetics, mass transfer, and reactor engineering. $\mathbf{1 6 0}$

Microreactor technologies have also been applied for biocatalytic transformation in ILs. ${ }^{\mathbf{1 6 1 , 1 6 2 , 1 6 3}}$ Fig. 11 illustrates a segmented flow biocatalytic microreactor system coupling reaction with separation. ${ }^{164} \mathrm{~A}$ buffer-ionic liquid mixed solvent was applied to synthesize isoquercitrin by the hesperidinasecatalysed selective hydrolysis of rutin $(\mathrm{R})$ to produce quercetin (Q). Glycerol triacetate was used as a second phase in a segmented flow pattern to continuously extract the product (Q). The slug flow formed in microchannels by the two phases (glycine-sodium hydroxide:[Bmim] $\left[\mathrm{BF}_{4}\right]$ and glycerol triacetate in $1: 1, \mathrm{v} / \mathrm{v}$, ratio) led to enhancing heat and mass transfer and promoted the enzymatic reaction shortening the reaction time (up to four times increase in reaction rate), increasing the enzymatic reaction efficiency and reducing the synthesis costs. The hesperidinase IL-phase could be easily separated from the phase containing the product and reused at least 5 times, without any loss of activity.

\section{From thermosensitive ILs to Sponge-Like Ionic Liquids systems}

Temperature-responsive ILs are a new class of ionic liquids with thermoregulated behaviour. They can form a homogeneous mixture with the reactants and products at reaction temperature but separate from them afterwards, giving place to distinct phases at ambient conditions. This behaviour offers an interesting approach to overcome the problems of classical IL-based catalysis in terms of product separation, as well as for the recovery the IL/(bio)catalyst system for further reuse. ${ }^{\mathbf{1 6 5}}$

Phase transfer catalytic strategies based on thermoregulated-phases have been widely studied using different approaches. These systems are based in aqueous : organic biphasic media at room temperature. When the reaction system is heated, the catalyst would be transferred from the aqueous phase to the substrate containing organic phase where the reaction takes place. After reaction, the catalyst is transferred back to the aqueous phase upon cooling, leaving the products in the organic phase, which facilitates the separation of the catalyst and the purification of products.

As an example of metal-containing IL thermomorphic systems, the thermoresponsive polyether-substituted imidazolium cobalt tetracarbonyl salts, $\left.\left[\mathrm{H}\left(\mathrm{OCH}_{2} \mathrm{CH}_{2}\right)_{n} \mathrm{C}_{4} \mathrm{Im}\right]\left[\mathrm{Co}(\mathrm{CO})_{4}\right)\right](\mathrm{n}=8,15$, and 22$)$ were used for the hydroesterification of 4-isobutylstyrene with $\mathrm{CO}$ and methanol. At room temperature the system is biphasic and the IL-catalysts are insoluble in a THF/heptane mixture containing the substrates. When heated above the critical solution temperature (CST, $82{ }^{\circ} \mathrm{C}$ in this case), the IL-catalysts are completely soluble in the mixture of organic solvents. Thus, the system becomes homogeneous and suitable for the proposed transformation. After cooling below the CST, the system becomes biphasic again, and this is accompanied by the separation of the products, retained in the organic phase, from the IL-catalysts phase. ${ }^{\mathbf{1 6 6}}$

Polyoxometalated ILs (POM-ILs) are another class of ILcatalytic phases exhibiting switchable properties based on temperature variation. An representative example is the $\left.\left[\left(\mathrm{CH}_{3}\right)_{3} \mathrm{NCH}_{2} \mathrm{CH}_{2} \mathrm{OH}\right]_{5} \mathrm{PV}_{2} \mathrm{Mo}_{10} \mathrm{O}_{40}\right)$ POM-IL that is fully immiscible with aqueous media at room temperature. It is, however, fully miscible with them at $70^{\circ} \mathrm{C}$, being then suitable to catalyse the oxidation of starch by hydrogen peroxide, showing a higher efficiency than traditional catalysts, such as $\mathrm{FeSO}_{4}$. When decreasing the temperature, the catalyst precipitates and becomes easily separable from the reaction mixture for further reuse without appreciable loss of its activity. ${ }^{\mathbf{1 6 7}}$ A second example took advantage of the thermoregulated solubility of poly(ethylene glycol) functionalized with alkylimidazolium cations (PEG-ILs) in ethyl acetate. ${ }^{\mathbf{1 6 8}}$ Thus, an IL consisting of a POM anion and a PEG-based dication was successfully used for the temperaturecontrolled catalytic epoxidation of various olefins following a similar heating/cooling approach for the catalytic and catalyst/products separation steps. ${ }^{\mathbf{1 6 9}}$

Polymeric ionic liquids (PILs) have been pursued for developing new advanced materials with improved physicochemical features that include self-healing, chirality or thermosensitivity. Such materials can provide all beneficial properties of classical ILs without many of their associated drawbacks. ${ }^{170}$ Chiral-polymeric ionic liquids (CPILs) having LCST-type phase transition behaviour have successfully been prepared. They made available smart nanogels fully soluble in 


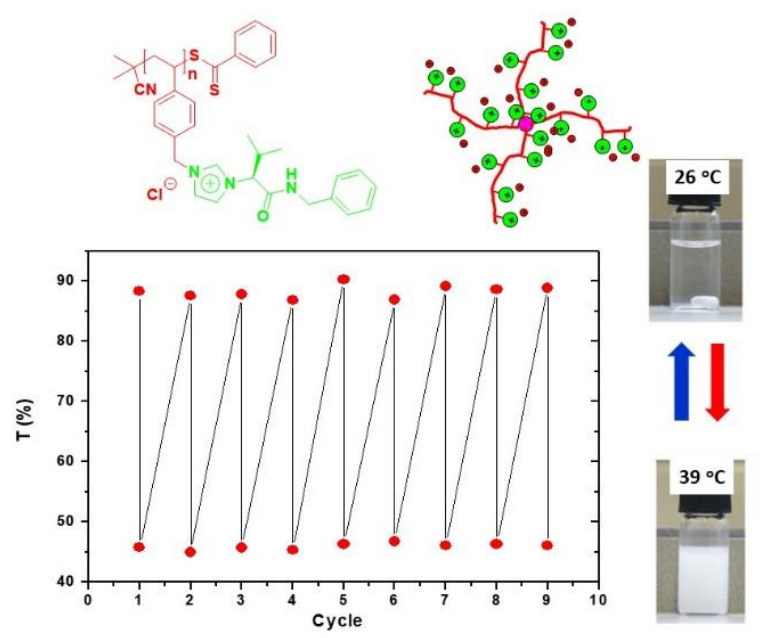

Fig. 12. Temperature-dependent behaviour of a CPIL-based on imidazolium cations in $\mathrm{CHCl}_{3}$, below LCST and above LCST. The curves show the change in transmittance $(660 \mathrm{~nm})$ with temperature for this solution in the heating and cooling processes. ${ }^{171}$

chloroform at room temperature but the solution becoming turbid when the temperature was increased (Fig 12). ${ }^{\mathbf{1 7 1}}$ This phenomenon is reversible when the stimulus is reversed and the CPIL re-dissolved upon cooling. CPILs prepared by controlled radical polymerization of monomeric units containing chiral ionic liquids (CILs) afford intrinsically chiral polymers with a well-defined three-dimensional structure organized as the result of a complex non-covalent network of hydrogen-bonding interactions. Some of them were able to catalyse the consecutive aldol-dehydration process, behaving as synthetic mimics of the aldolase-dehydrogenase enzymatic system. ${ }^{\mathbf{1 7 2}}$

Among the thermoresponsive ILs approaches, the term sponge-like ionic liquids (SLILs) has been coined for those hydrophobic ILs based on a long alkyl side-chain in the cation, with melting points higher than room temperature, that behave as temperature switchable ionic liquid/solid phases (i.e. 1octadecyl-3-methylimidazolium bistriflymide, [C $18 \mathrm{mim}]\left[\mathrm{NTf}_{2}\right]$, 173 or 1-hexadecyltrimethylammonium bistriflymide, $\left.\left[\mathrm{C}_{16} \mathrm{tma}_{[\mathrm{NTf}}\right]^{174}\right)$. At temperatures higher than the melting point, these SLILs are liquids and show an excellent ability to dissolve hydrophobic compounds (i.e. methyl oleate, geraniol, nerol, citronellol, etc.), resulting in fully clear monophasic systems. Nevertheless, this SLIL-solute mixture becomes a solid just by cooling down to room temperature, being the solute caught in the solid IL net. An amazing feature of these SLILs occurs when the SLIL-solute solid mixtures are centrifuged at a temperature lower than room temperature, because the IL behaves as a sponge releasing the liquid solute ("sponge wrung out") to the upper phase, while the solid IL remains at the bottom phase. By using centrifugal filters, the solid IL is retained by the membrane, while the liquid solute phase passes to the bottom of the tube as the result of the action of the centrifugal force. ${ }^{37}$ By using a 50/50 (w/w) $\left[\mathrm{C}_{16 \mathrm{tma}}\right]\left[\mathrm{NTf}_{2}\right] /$ geranyl acetate mixture as representative example, it was obtained an IL-free flavour fraction by following an iterative centrifugation protocol of four steps (10 min, 14,000 rpm) and lowering the temperature from room

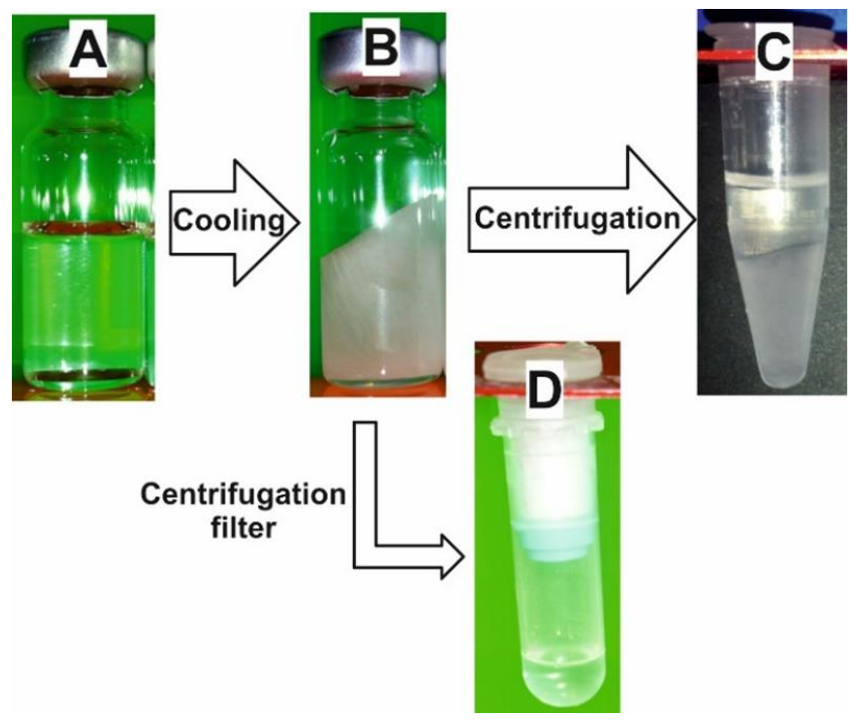

Fig. 13. Sponge-like behaviour of a $50 / 50(\mathrm{w} / \mathrm{w})$ geranyl acetate/[C18mim] $\left[\mathrm{NTf}_{2}\right]$ mixture: 60 ㅇ ( (Liquid, A), 25 ㅇ (Solid, B), after four consecutive centrifugation steps (i.e. room temperature, 21, 10 and $4 \stackrel{\circ}{\circ}$ )(Two Phases, C), and after filtration through centrifugal nylon filters $\left(0.2 \mu \mathrm{m}\right.$ pore size, D). ${ }^{4 b, 37,174,178}$

temperature $\left(25^{\circ} \mathrm{C}\right.$ approx.) to $4{ }^{\circ} \mathrm{C}$ (see Fig. 13). It should be noted, however, that a full release of the flavour was not observed in any case after centrifugation. For example, by using the same separation protocol in four 50/50 (w/w) $\left[\mathrm{C}_{16}\right.$ tma] $\left[\mathrm{NTf}_{2}\right] /$ flavour mixtures, the flavour released diminished as the size of the alkyl chain fragment in the flavour increased: isoamyl acetate (82\%), neryl acetate (60\%), citronellyl acetate $(59 \%)$, geranyl acetate $(51 \%)$, probably as a result of the stronger interaction with the alkyl chain of the IL. These results were not improved by increasing the centrifugation time and/or the centrifugation speed. ${ }^{\mathbf{1 7 4}}$ Furthermore, these SLILs showed a "wet sponge" behaviour during reuse after each cycle of "soaking/wringing".

This unique feature of SLILs was explained as a function of the solid/liquid structural organization of ILs, and the interactions with solute molecules induced by these structural characteristics. Indeed, hydrophobic compounds may be considered as being included rather than dissolved in the liquid/solid IL phases, and the decrease in free volume of the ionic net produced by cooling and centrifugation, led to the

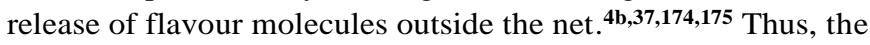
IL net can be considered as a nano-sponge with holes of variable volume, which are suitable for housing or releasing hydrophobic molecules as a function of their liquid or solid phase, respectively.

Furthermore, the excellent suitability of SLILS for carrying out biocatalytic processes is another important feature to be underlined. Water-immiscible ILs, such as these SLILs have been shown as exceptionally suitable reaction media for enzyme-catalysed reactions, ${ }^{4 \mathbf{b}, 11 a}$ probably due to their hygroscopic character $\left(e . g\right.$. [Bmim] $\left[\mathrm{NTf}_{2}\right]$ is able to absorb up to $1.4 \% \mathrm{w} / \mathrm{w}$ water content), ${ }^{\mathbf{1 7 6}}$ which provides the essential 
degree of hydration around enzyme molecules, maintaining the catalytic function in these non-aqueous environments.

In this context, it was reported how immobilized lipase was suitable to catalyse the synthesis of different flavour esters including geranyl acetate, ${ }^{\mathbf{1 7 4}}$ anisyl acetate, ${ }^{\mathbf{1 7 7}}$ cinnamyl proprionate, ${ }^{178}$ by the esterification reaction between the corresponding alcohol (i.e. geraniol, anisyl alcohol, cinnamyl alcohol, etc.) and pure acetic acid in SLILs, simplifying separation procedures as indicated above. The reaction was quite efficient with product yields higher than $80 \%$ at $50^{\circ} \mathrm{C}$ after 1-2 $\mathrm{h}$. This efficiency was improved by the assistance of microwave irradiation $(100 \%$ yield after $30 \mathrm{~min}$ at $4 \mathrm{~W}$ MW). ${ }^{177}$ Furthermore, SLILs protect enzymes against denaturation by both temperature and acid concentration phenomena, the biocatalytic activity being maintained at the highest level during several cycles of reuse, which could be attributed to the ability of SLIL to act as a "mould" to maintain the active conformation of the enzyme.

The biocatalytic synthesis of biodiesel in SLILs can be taken as a representative example of a clean process carried out by this thermosensitive technology. Classical ILs used in biocatalysis like $[\mathrm{Bmim}]\left[\mathrm{NTf}_{2}\right]$ are unable to overcome the first technical problem for producing biodiesel, as is the mutual immiscibility between vegetable oils and methanol, resulting in two-phase reaction systems. However, SLILs like $\left[\mathrm{C}_{18} \mathrm{mim}\right]\left[\mathrm{NTf}_{2}\right]$ were able to simultaneously dissolve both the methanol and the vegetable oil by forming monophasic reaction system. ${ }^{179}$ This provided an excellent microenvironment for carrying out the biocatalytic synthesis of biodiesel, with up to $92 \%$ biodiesel yield after $8 \mathrm{~h}$. In this context, the suitability of ILs based on the [NTf 2 ] anion and imidazolium or ammonium cations having an alkyl chain length larger than 12 carbons to form monophasic liquid systems by dissolving vegetable oil and methanol, has been reported. ${ }^{173}$ Furthermore, it should be noted that these SLILs provide excellent stabilization of the immobilized enzyme against temperature, being observed very weak activity decays (c.a. $10 \%$ ) after 100 days of incubation in a $50 \%(\mathrm{w} / \mathrm{w})$ triolein/[C $\left.\mathrm{C}_{18} \mathrm{tma}\right]\left[\mathrm{NTf}_{2}\right]$ mixture at $60{ }^{\circ} \mathrm{C}$ (ca. 1,200 days halflife). ${ }^{175}$

Based on the genuine properties of these SLILs, the integration of both the biocatalytic reaction and the product separation steps was carried out by a straightforward protocol, suitable for scaling up the production of biodiesel. Taking into account that biodiesel and glycerol are the reaction products, the general procedure developed for separating both compounds from SLILs was customized by introducing water as a new green solvent in the system to provide a new hydrophilic phase to extract the glycerol. As can be seen in Fig. 14 , the addition of hot water $\left(60^{\circ} \mathrm{C}\right)$ to the resulting monophasic system after the biocatalytic step, followed by cooling to room temperature, led to a milky heterogeneous mixture, which was then separated by following an iterative cooling/centrifugation protocol $(15,000 \mathrm{rpm}, 1 \mathrm{~h}$ at room temperature, 23 and $15^{\circ} \mathrm{C}$, respectively). By this approach, the heterogeneous mixture was separated into three phases: an upper IL-free biodiesel phase, a middle IL-free liquid aqueous phase containing the glycerol, and a solid at the bottom

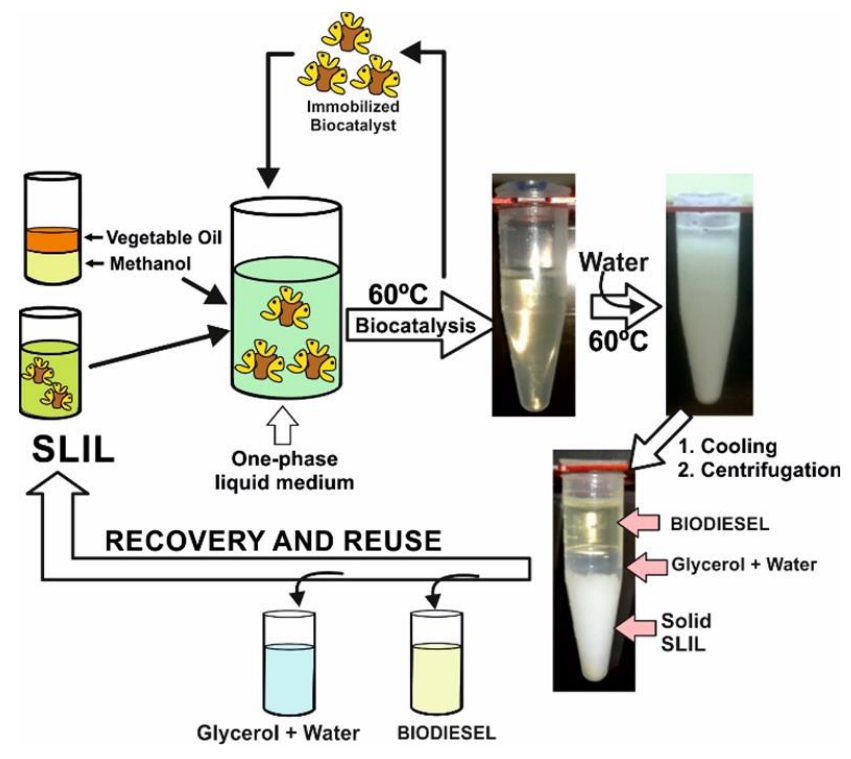

Fig. 14. Clean protocol for the biocatalytic production of biodiesel using SpongeLike Ionic Liquids (SLILs), integrating both the biocatalytic and the separation steps with the full recovery and reuse of the SLIL/biocatalyst system. ${ }^{175,180}$

containing the SLIL. ${ }^{\mathbf{4 b}, \mathbf{1 7 5}, \mathbf{1 7 7}}$ By means of this approach, the biocatalyst/SLIL system was fully recovered and reused, highlighting the suitability of this clean methodology for producing biodiesel with easy implementation at industrial level. The suitability of this proposed approach based on these thermosensitive SLILs for the biocatalytic synthesis of biofuels from triacylglycerides obtained from different sources (waste cooking oils or cotton seeds) has also been reported. ${ }^{\mathbf{1 8 0}}$

In an attempt to develop an integral sustainable process for producing biofuels, binary mixtures of ILs have been used for developing one-pot systems suitable for the direct extraction of algal oil from raw material (i.e. Chlorella vulgaris), followed by its biocatalytic transformation to biodiesel and a final biofuel extraction. These mixtures were based on the combination of SLILs with [Bmim][Cl], taking into account the excellent suitability to carry out the biocatalytic synthesis of biodiesel of the first one, and the ability for dissolving cellulosic biomass of the second. The extraction of oils was carried out by incubating the dry microalgae in the appropriated IL binary mixture at $110^{\circ} \mathrm{C}$, which after being cooled at $60^{\circ} \mathrm{C}$ allowed to be transformed to biodiesel by an immobilized lipase. This resulted in a fast and efficient biodiesel synthesis, with up to $100 \%$ yield in $2 \mathrm{~h}$ at $60^{\circ} \mathrm{C}$. The subsequent cooling until room temperature and the iterative centrifugation of the resulting semi-solid systems at 20 and $18^{\circ} \mathrm{C}$ led to the separation of the liquid algae-based biodiesel from the solid IL mixture, which was recovered and reused for a further operation cycle. ${ }^{\mathbf{1 8 1}}$

\section{Conclusions and overlook.}

Chemistry has played a key role in the continuous improvement of our quality of life, and there is no doubt that the necessary improvements and solutions to alleviate the 
environmental impact of chemical industries will be found by Chemistry and by chemists with sustainability criteria. Although the use renewable sources of energy and /or matter is key in this field, new achievements in chemistry and chemical engineering focusing on the continuous improvement in the efficiency of chemical transformations and processes, quite particularly products and catalyst recovery, are essential in order to provide new opportunities for further generations. Nature should be taken as a source of inspiration for chemists, providing tools (catalysts, materials, etc.) and experimental approaches to reach the maximum catalytic efficiency for obtained the desired products with a minimum production of waste and the integration of transformation and separation steps represent an important contribution towards this target.

Ionic liquids and their technological developments open daily new avenues in the context of sustainable chemistry technologies, as an important enabling tool to integrate reaction and separation processes. The excellences of many different catalysts like enzymes or MNPs, can be greatly improved in ILs, $\mathrm{scCO}_{2}$ and/or $\mathrm{IL} / \mathrm{scCO}_{2}$ environments with excellent synergies, allowing the integral design of clean synthetic processes. These IL-based systems can contribute not only to the stabilization and easy recycling of the (bio)catalysts but can also be easily implemented in flow systems for further process improvements.

Many different approaches can be used for this purpose: membrane reactors; microfluidic devices; droplet Pickering emulsions microsystems; $\mathrm{IL} / \mathrm{scCO}_{2}$ biphasic reactors using supported ionic liquid phases, thermosensitive ILs, SLILs, etc. Many of them allow the integration of reaction and separation steps in chemical production, in particular under continuous flow conditions. The combination of efficient biocatalysts and/or chemocatalysts with advanced materials based on supported ionic liquids (SILPS or SILLPs) offers new opportunities that directly point to the integration of several catalytic steps in multi-step organic syntheses with the downstream processing, without the need to isolate intermediates, mimicking the metabolic pathways found in Nature.

In the same context, thermosensitive ILs based technologies, especially considering ILs with sponge-like behaviour (SLILs) allow the development of straightforward and clean approaches for efficiently separating a liquid and hydrophobic organic compound (i.e. flavours, biodiesel, etc.) from homogeneous ionic liquid/organic compound mixtures using a simple cooling and centrifugation approach, a technology easily transferable to a higher scale.

However, all the excellences of ILs for developing integrated reaction and separation processes are tarnished by their toxicity and/or environmental footprint. Used in large volume, it is inevitable that small amounts of ILs could escape into the environment, and both their immediate impact on the local ecosystem and also their ultimate biodegradation need to be carefully considered. ${ }^{\mathbf{2 3 , 2 8}}$ The development of new synthetic strategies, based on the use of 'greener', safer, and less harmful compounds for producing new non-toxic and biodegradable Bio-ILs, suitable to retain the unique features of commonly used ILs (e.g. negligible vapour pressure, solvent power, tunability, etc.) is a key aim nowadays. In a further step, the preparation and application of tailor-made poly Bio-ILs, suitable to act as nanomaterials with enzymatic catalytic properties (nanozymes, or artificial enzymes), showing high substrate selectivity as well as catalytic efficiency, is a clear target in the research agenda. ${ }^{\mathbf{1 8 2}}$

The combination of both the ILs and the (bio)catalyst technologies has opened the way to a broad range of sustainable approaches enabling the integration of chemical transformations and product separation processes, many of them suitable for implementation at industrial scale. From green chemistry to "dream" chemistry, there is a path under construction.

\section{Acknowledgements}

This work has been partially supported by CTQ-2015-67927-R (MINECO/FEDER), RTI2018-098233-B-C21 and RTI2018098233-B-C22 (MICINN), PROMETEO/2016/071 (Generalitat Valenciana) and 20790/PI/18 (Fundacion SENECA CARM) grants

\section{Notes and references}

a Departamento de Bioquímica y Biología Molecular "B” e Inmunología. Facultad de Química. Campus de Excelencia Internacional Mare Nostrum, Universidad de Murcia. E-30.100. Murcia. Spain.E-mail: plozanor@um.es

${ }^{b}$ Departamento de Química Inorgánica y Orgánica, Universidad Jaume I, Campus del Riu Sec, Avenida Sos Baynant s/n, E-12071, Castellón, Spain.

In memoriam to Inorganic Chemistry Professor Gregorio Sánchez-Gómez, died at July $12^{\text {th }}, 2019$.

1 a) P. T. Anastas and J. C.Warner, Green Chemistry: Theory and Practice, Oxford University Press: New York, 1998; b) P. T. Anastas and J. B. Zimmerman, Environ. Sci. Technol, 2003, 37, 94A-101A.

2 H. C. Erythropel, J. B. Zimmerman, T. M. de Winter, L. Petitjean, F. Melnikov, C.Ho Lam, A. W. Lounsbury, K. E. Mellor, N. Z. Janković, Q. Tu, L. N. Pincus, Mark M. Falinski, W. Shi, P. Coish, D. L. Plata and P. T. Anastas, Green Chem., 2018, 20, 1929-1961.

3 a) J. D. Scholten, B. C. Leal and J. Dupont, ACS Catal. , 2012, 2, 184-200; b) A. Dhakshinamoorthy, A. M. Asiri, M. Alvaro and H. Garcia. Green Chem., 2018, 20, 86-107.

4 a) R. A. Sheldon and J. M. Woodley, Chem. Rev., 2018, 118, 801-838; b) P. be, J. M. Bernal, S. Nieto, C. Gomez, E. Garcia-Verdugo and S.V. Luis, Chem. Commun., 2015, 51, 17361-17374.

5 P. T. Anastas, Trends Chem., 2019, 1, 145-148.

6 C. Jimenez-Gonzalez, Curr. Opin. Green Sustain. Chem. 2019, 18, 6671. 
7 W. Keim, Green Chem., 2003, 5, 105-111.

8 D. J. C. Constable, P. J. Dunn, J. D. Hayler, G. R. Humphrey, J. L. Leazer Jr., R. J. Linderman, K. Lorenz, J. Manley, B. A. Pearlman, A. Wells, A. Zaks and T. Y. Zhang, Green Chem. 2007, 9, 411-420.

9 C. Seyler, C. Capello, S. Hellweg, C. Bruder, D. Bayne, A. Huwiler and K. Hungerbühler, Ind. Eng. Chem. Res.2006, 45, 7700-7709.

10 C. J. Clarke, W. C. Tu, O. Levers, A. Bröhl and J. P. Hallett, Chem. Rev., 2018, 118, 747-800.

11 a) P. Lozano. Green Chem., 2010, 12, 555-569; b) C. J. Li and P. T. Anastas, Chem. Soc. Rev., 2012, 41, 1413-1414.

12 R. A. Sheldon, Curr. Opin. Green Sustain. Chem., 2019, 18, 13-19.

13 S. Abou-Shehada, J. H. Clark, G. Paggiola and J. Sherwood, Chem. Eng. Process., 2016, 99, 88-96.

14 C. Capello, U. Fischer and K. Hungerbühler, Green Chem., 2007, 9, 927-934.

15 S. Mayadevi, in Industrial Catalysis and Separations: Innovations for Process Intensification, ed. K. V. Raghavan and B. M. Reddy, Apple Acad. Press Inc, Oakville, 2015, pp. 219-246.

16 G. Brunner, J. Supercrit. Fluids, 2009, 47, 373-381.

17 C. S. Slater, M. J. Savelski, D. Hitchcock and E. J. Cavanagh, J. Environ. Sci. Heal A., 2016, 51, 487- 494.

18 D. M. Alonso, S. G. Wettstein and J. A. Dumesic, Green Chem., 2013, 15, 584-595.

19 E. C. Camp, ChemSusChem, 2018, 11, 3048-3055.

20 P. Pollet, E. A. Davey, E. E. Ureña-Benavides, C. A. Eckert and C. L. Liotta, Green Chem., 2014, 16, 1034-1055.

21 J. P. Hallett and T. Welton, Chem. Rev., 2011, 111, 3508-3576.

22 a) J. Dupont, R. F. de Souza and P. A. Z. Suarez, Chem. Rev., 2002, 102, 3667-369; b) T. Welton, Coord. Chem. Rev., 2004, 248, 2459-2477.c) C. Chiappe and D. Pieraccini, J. Phys Org. Chem., 2005, 18, 275-297.

23 D. R. MacFarlane, M. Kar and J. M. Pringle, Fundamentals of Ionic Liquids: From Chemistry to Applications, Wiley-VCH, Verlag, Weinheim 2017.

24 a) Y. Zhang, B R. Bakshi, and E. S. Demessie, Environ. Sci. Technol., 2008, 42, 1724-1730; b) G. Cevasco and C. Chiappe, Green Chem., 2014, 16, 2375-2385.

25 V. Gonçalves, M. Dominic, J. Walesc, M. Seferin, C. M. L. Ugay and V. Sans, J. Clean. Prod., 2019, 217, 844-858.

26 a) P. D. de Maria, Angew. Chem. Int Ed., 2008, 47, 6960-6968; b) F. Javed, F. Ullah, M. R. Zakaria and H. M. Akil, J. Mol. Liq., 2018, 271, 403-420.

27 H. Ohno, M. Yoshizawa-Fujita and Y. Kohno, Bull. Chem. Soc. Jpn, 2019, 92, 852-868.

28 J. M. Gomes, S. S. Silva and R. L. Reis, Chem. Soc. Rev., 2019, 48, 43174335.

29 P. Lozano, Sustainable Catalysis in Ionic Liquids. CRC Press, New York, 2018.

30 a) S. N. Baker, T. M. McCleskey, S. Pandey and G. A. Baker. Chem. Commun, 2004, 940-941; b) T. De Diego, P. Lozano, S. Gmouh, M. Vaultier and J. L. Iborra, Biotechnol. Bioeng. 2004, 88, 916-924; c) T. De
Diego, P. Lozano, S. Gmouh, M. Vaultier, J.L. Iborra, Biomacromolecules, 2005, 6, 1457-1464.

31 J. Zhou, H. Sui, Z. Jia, Z. Yang, L.He and X. Li, RSC Adv., 2018, 8, 32832-32864.

32 L. Gubicza, N. Nemestothy, T. Frater and K. Belafi-Bako. Green Chem., 2003, 5, 236-239.

33 C. Q. Yao, Y. C. Zhao, G. W. Chen, Chem. Eng. Sci., 2018, 189, 340359.

34 a) L. A. Blanchard, D. Hancu, E.J . Beckman, J. F. Brennecke, Nature, 1999, 399, 28-29; b) L. A. Blanchard, Z. Y. Gu, J. F. Brennecke, J. Phys. Chem. B, 2001, 105, 2437-2444.

35 P. Lozano, E. Garcia-Verdugo, N. Karbass, K. K. Montague, T. De Diego, M. I. Burguete and S. V. Luis, Green Chem., 2010, 12, 1803-1810.

36 E. Garcia-Verdugo, B. Altava, M. I. Burguete, P. Lozano and S. V. Luis, Green Chem., 2015, 17, 2693-2713.

37 P. Lozano, J. M Bernal, E. Garcia-Verdugo, G. Sanchez-Gomez, M. Vaultier, M. I. Burguete and S. V. Luis, Green Chem., 2015, 17, 37063717.

38 B. Altava, M. I. Burguete, E. Garcia-Verdugo and S. V. Luis, Chem. Soc. Rev., 2018, 47, 2722-2771.

39 V. Farmer and T. Welton, Green Chem., 2002, 4, 97-102.

40 T. Itoh, E. Akasaki and Y. Nishimura. Chem. Lett., 2002, 154-155.

41 H. Passos, A. Luis, J. A. P. Coutinho and M. G. Freire, 2016. Sci. Rep. 2016, art. no. 20276.

42 F. A. E. Silva, J. F. B. Pereira, K. A. Kurnia, S. P. M. Ventura, A. M. S. Silva, R. D. Rogers, J. A. P. Coutinho and M. G. Freire, Chem. Commun., 2017, 53, 7298-7301.

43 K. Fukumoto and H. Ohno, Angew. Chem. Int. Ed., 2007, 46, 1852-1855.

44 A. M. Ferreira, H. Passos, A. Okafuji, A. P. M. Tavares, H. Ohno, M. G. Freire and J. A. P. Coutinho, Green Chem., 2018, 20, 1218-1223.

45 M. Pera-Titus, L. Leclercq, J. M. Clacens, F. De Campo and V. Nardello-Rataj, Angew. Chem. Int. Ed., 2015, 54, 2006-2021.

46 Y. Q. Yang, Z. W. Fang, X. Chen, W. W. Zhang, Y. M. Xie, Y. H. Chen, Z. G. Liu and W. E. Yuan, Front Pharmacol., 2017, 8, art. no. 287.

47, H. Q. Yang, L. M. Fu, L. J. Wei, J. F. Liang and B. P. Binks, J. Am. Chem. Soc., 2015, 137, 1362-1371.

48 S. Crossley, J. Faria, M. Shen and D. E. Resasco, Science, 2010, 327, 68-72.

49 P. A. Zapata, J. Faria, M. P. Ruiz and D. E. Resasco, Top. Catal., 2012, 55, 38-52.

50 J, Faria, M. P. Ruiz and D. E. Resasco, Adv. Synth. Catal., 2010, 352, 2359-2364.

51 M. Zhang, R. Ettelaie, T. Yan, S. J. Zhang, F. Q. Cheng, B. P. Binks and H. Q. Yang. J. Am. Chem. Soc. 2017, 139, 17387-17396.

52 Z. Meng, M. Zhang and H. Yang, Green Chem., 2019, 21, 627-633.

53 X. Zhang, Y. Hou, R. Ettelaie, R. Guan, M. Zhang, Y. Zhang and H. Yang, J. Am. Chem. Soc., 2019 141, 5220-5230.

54 Y. Gao, N. Li, L. Q. Zheng, X. Y. Zhao, S. H. Zhang, B. X. Han, W. G. Hou, and G. Z. Li. Green Chem., 2006, 8, 43-49. 
55 C. X. Zeng, S. J. Qi, Z. G. Li, R. M. Luo, B. Yang and Y. H. Wang, Bioproc. Biosyst. Eng., 2015, 38, 939-946.

56 S. Keskin, D. Kayrak-Talay, U. Akman and O. Hortaçsu, J. Supercrit. Fluids, 2007, 43, 150-180.

57 L. A. Blanchard, Z. Y. Gu and J. F. Brennecke, J. Phys. Chem. B, 2001, 105, 2437-2444.

58 R. Liu, P. Zhang, S. Zhang, T. Yan, J. Xin and X. Zhang, Rev. Chem. Eng., 2016, 32, 587-609.

59 F. Jutz, J.-M. Andanson and A. Baiker, Chem. Rev., 2011, 111, 322-353.

60 J. Szyling, A. Franczyk, K. Stefanowska, H. Maciejewski and J. Walkowiak, ACS Sustain. Chem. Eng., 2018, 6, 10980-10988.

61 C. Y. Shi, J. Y. Xin, X. M. Liu, X. M. Lu and S. J. Zhang, ACS Sustain. Chem. Eng., 2016, 4, 557-563.

62 Y. Hiraga, A. Duereh and R. L. Smith, J. Supercrit. Fluids, 2018, 134, $12-20$.

63 E. Peris, R. Porcar, J. Garcia-Alvarez, M. I. Burguete, E. GarciaVerdugo and S. V. Luis, ChemSusChem, 2019, 12, 1684-1691.

64 Y. Medina-Gonzalez, S. Camy and J. S. Condoret, ACS Sustain. Chem. Eng., 2014, 2, 2623-2636.

$65 \mathrm{~J}$. Walkowiak, G. Francio and W. Leitner, in Applied Homogeneous Catalysis with Organometallic Compounds, eds. B. Cornils, W. A. Herrmann, M. Beller and R. Paciello, Wiley-VCH Verlag, Weinheim, $3^{\text {rd }}$ edn, 2017, ch. 20, pp. 1221-1258.

66 W. Leitner, Acc. Chem. Res., 2002, 35, 746-756.

67 C. Van Doorslaer, J. Wahlen, P. Mertens, K. Binnemans and D. De Vos, Dalton Trans. 2010, 39, 8377-8390.

68 R. Fehrmann, A. Riisager and M. Haumann, Supported Ionic Liquids: Fundamentals and Applications, Wiley-VCH Verlag, Weinheim, 2014.

69 S. G. Zhang, J. H. Zhang, Y. Zhang and Y. Q. Deng, Chem. Rev., 2017, 117, 6755-6833.

70 A. Riisager, P. Wasserscheid, R. van Hal and R. Fehrmann, J. Catal., 2003, 219, 452-455.

71 A. Riisager, K. M. Eriksen, P. Wasserscheid and R. Fehrmann, Catal. Lett., 2003, 90, 149-153.

72 M. Haumann, K. Dentler, J. Joni, A. Riisager and P. Wasserscheid, Adv. Synth. Catal., 2007, 349, 425-431.

73 J. M. Marinkovic, A. Riisager, R. Franke, P. Wasserscheid and M. Haumann, Ind. Eng. Chem. Res., 2019, 58, 2409-2420.

74 M. A. Gelesky, S. S. X. Chiaro, F. A. Pavan, J. H. Z. dos Santos and J. Dupont, Dalton Trans., 2007, 5549-5553.

75 M. Ruta, I. Yuranov, P. J. Dyson, G. Laurenczy and L. Kiwi-Minsker, J. Catal., 2007, 247, 269-276.

76 J. Brunig, Z. Csendes, S. Weber, N. Gorgas, R. W. Bittner, A. Limbeck, K. Bica, H. Hoffmann, K. Kirchner, ACS Catal., 2018, 8, 1048-1051.

77 U. Hintermair, T. Hofener, T. Pullmann, G. Francio and W. Leitner, Chem CatChem, 2010, 2, 150-154.

78 A. Riisager, B. Jorgensen, P. Wasserscheid and R. Fehrmann, Chem. Commun., 2006, 994-996.
79 S. Werner, N. Szesni, R. W. Fischer, M. Haumann and P. Wasserscheid, Phys. Chem. Chem. Phys., 2009, 11, 10817-10819.

80 R. Kukawka, A. Pawlowska-Zygarowicz, J. Dzialkowska, M. Pietrowski, H. Maciejewski, K. Bica and M. Smiglak, ACS Sustain. Chem. Eng., 2019, 7, 4699-4706.

81 G. Francio, U. Hintermair and W. Leitner, Philos. Trans. R. Soc. A, 2015, 373, art no 20150005.

82 M. Haumann and P. Wasserscheid, in Applied Homogeneous Catalysis with Organometallic Compounds, eds. B. Cornils, W. A. Herrrmann, M. Beller and R. Paciello, Wiley-VCH Verlag, Weinheim, $3^{\text {rd }}$ edn, 2017, ch. 14, pp. 999-1068.

83 a) P. Lozano, T. De Diego, D. Carrié, M. Vaultier, J. L. Iborra, Chem. Commum., 2002, 692-693; b) M. T. Reetz, W. Wiesenhofer, G. Francio and W. Leitner, Chem. Commun., 2002, 992-993.

84 T. Itoh, Chem. Rev., 2017, 117, 10567-10607.

85 P. Lozano, T. De Diego, C. Mira, K. Montague, M. Vaultier and J. L. Iborra. Green Chem., 2009, 11, 538-542.

86 M. Abai, M. P. Atkins, A. Hassan, J. D. Holbrey, Y. Kuah, P. Nockemann, A. A. Oliferenk, N. V. Plechkova, S. Rafeen, A. A. Rahman, R. Ramli, S. M. Shariff, K. R. Seddon, G. Srinivasan and Y. Zou, Dalton Trans., 2015, 44, 8617-8624.

87 https://corporate.evonik.com/en/Pages/article.aspx?articleId=106423.

88 a) B. H. Xu, J. Q. Wang, J. Sun, Y. Huang, J. P. Zhang, X. P. Zhang and S. J. Zhang, Green Chem., 2015, 17, 108-122; b) http://english.ipe.cas.cn/ic/ic/201905/t20190519_209890.html.

89 P. Zhang, P. Wu and B. Han, Adv. Mater., 2014, 26, 6810-6827.

90 W. J. Qian, J. Texter and F. Van, Chem. Soc. Rev., 2017, 46, 1124-1159.

91 A. Eftelchari and T. Saito, Eur. Polym. J., 2017, 90, 245-272.

92 V. Campisciano, F. Giacalone and M. Gruttadauria, Chem. Rec., 2017, 17, 918-938.

93 B. Xin and J. Hao, Chem. Soc. Rev., 2014, 43, 7171-7187.

94 M. H. Valkenberg, C. de Castro and W. F. Holderich, Green Chem., 2002, 4, 88-93.

95 a) M. I. Burguete, F. Galindo, E. Garcia-Verdugo, N. Karbass and S. V. Luis, Chem. Commun., 2007, 3086-3088; b) C. Chiappe, C. S. Pomelli and S. Rajamani, J. Phys. Chem. B, 2011, 115, 9653-9661.

96 S. Montolio, B. Altava, E. Garcia-Verdugo and S. V. Luis, in Green Synthetic Processes and Procedures, ed. R. Ballini, RSC Green Chemistry Series, Cambridge, 2019. ch. 13, pp. 289-318.

97 D. Xu, J. Guo and F. Yan, Progr. Polym. Sci., 2018, 79, 121-143.

98 F. Giacalone and M. Gruttadauria, ChemCatChem, 2016, 8, 664-684.

99 S. Zhang, K. Dokko and M. Watanabe, Chem. Sci., 2015, 6, 36843691 .

100 V. Sans, N. Karbass, M. I. Burguete, V. Compan, E. Garcia-Verdugo, S. V. Luis and M. Pawlak, Chem. Eur. J., 2011, 17, 1894-1906.

101 A. Castro-Grijalba, E. M. Reyes-Gallardo, R. G. Wuilloud, R. Lucena and S. Cardenas, RSC Adv., 2017, 7, 42979-42985.

102 a) A. Garcia-Bernabe, A. Rivera, A. Granados, S. V. Luis and V. Compan, Electrochim. Acta, 2016, 213, 887-897; b) B. Altava, V. 
Compan, A. Andrio, L. F. del Castillo, S. Molla, M. I. Burguete, E. Garcia-Verdugo and S.V. Luis, Polymer, 2015, 72, 69-81.

103 M. Gruttadauria, L. F. Liotta, A. M. P. Salvo, F. Giacalone, V. La Parola, C. Aprile and R. Noto, Adv. Synth. Catal., 2011, 353, 21192130.

104 P. Agrigento, S. M. Al-Amsyar, B. Sorée, M. Taherimehr, M. Gruttadauria, C. Aprile and P. Pescarmona, Catal. Sci. Technol., 2014, 4, 1598-1607.

105 S. Martin, R. Porcar, E. Peris, M. I. Burguete, E. Garcia-Verdugo, S. V. Luis, Green Chem., 2014, 16, 1639-1647.

106 T. Wang, W. L. Wang, Y. Lyu, X. K. Chen, C. Y. Li, Y. Zhang, X. G. Song, Y. J. Ding, $R S C A d v$., 2017, 7, 2836-2841.

107 P. Lozano, E. Garcia-Verdugo, R. Piamtongkam, N. Karbass, T. De Diego, M. I. Burguete, S. V. Luis and J. L. Iborra, Adv. Synth. Catal., 2007, 349, 1077-1084.

108 D. F. Izquierdo, J. M. Bernal, M. I. Burguete, E. Garcia-Verdugo, P. Lozano and S. V. Luis, RSC Adv., 2013, 3, 13123-13126.

109 P. Lozano, E. Garcia-Verdugo, J. M. Bernal, D. I. Izquierdo, M. I. Burguete, G. Sánchez-Gómez and S. V. Luis, ChemSusChem, 2012, 5, 790-798.

110 P. Lozano, E. Garcia-Verdugo, N. Karbass, K. Montague, T. De Diego, M. I. Burguete and S. V. Luis, Green Chem., 2010, 12, $1803-$ 1810.

111 R. Porcar, P. Lozano, M. I. Burguete, E. Garcia-Verdugo and S. V. Luis, React. Chem. Eng., 2018, 3, 572-578.

112 E. Peris, M. I. Burguete, R. Porcar, E. Garcia-Verdugo and S. V. Luis ChemCatChem, 2019, 7, 1955-1962.

113 J. D Scholten, B. C. Leal and J. Dupont, ACS Catal., 2012, 2, 184200.

114 K. L. Luska, P. Migowski and W. Leitner, Green Chem., 2015, 17, 3195-3206.

115 A. Mudhoo and G. Kumar, Biochem. Eng. J., 2018, 138 141-155.

116 G. Chacon and J. Dupont, ChemCatChem, 2019, 11, 333-341.

117 A. P. Umpierre, G. Machado, G. H. Fecher, J. Morais and J. Dupont. Adv. Synth. Catal., 2005, 347, 1404-1412.

118 S. G. Fonseca, J. D. Scholten and J. Dupont, Synlett, 2004, 1525-1528.

119 Z. He and P. Alexandridis, Phys. Chem. Chem. Phys., 2015, 17, 18238-18261.

120 M. I. Burguete, E. Garcia-Verdugo, S. V. Luis and J. Restrepo, Phys. Chem. Chem. Phys., 2011, 13, 14831-14838.

121 J. Restrepo, P. Lozano, M. I. Burguete, E. Garcia-Verdugo and S. V. Luis, ACS Catal., 2015, 5, 4743-4750.

122 J. Restrepo, P. Lozano, M. I. Burguete, E. Garcia-Verdugo and S. V. Luis, Catal. Today, 2015, 255, 97-101.

123 A. Dani, V. Crocella, L. Maddalena, C. Barolo, S. Bordiga and E. Groppo, J. Phys. Chem. C, 2016, 120, 1683-1692.

124 M. I. Burguete, E. Garcia-Verdugo, I. Garcia-Villar, F. Gelat, P. Licence, S. V. Luis and V. Sans, J. Catal., 2010, 269, 150-160.

125 N. Karbass, V. Sans, E. Garcia-Verdugo, M. I. Burguete and S. V. Luis, Chem. Commun., 2006, 29, 3095-3097.
126 K. L. Luska, P. Migowski, S. El Sayed, and W. Leitner, ACS Sustain. Chem. Eng., 2016, 4, 6186-6192.

127 M. L. Offner-Marko, A. Bordet, G. Moos, S. Tricard, S. Rengshausen, B. Chaudret, K. L. Luska and W. Leitner, Angew. Chem. Int. Ed., 2018, 57, 12721-12726.

128 V. Sans, F. Gelat, N. Karbass, M. I. Burguete, E. Garcia-Verdugo and S. V. Luis, Adv. Synth. Catal., 2010, 352, 3013-3021.

129 K. Belafi-Bako, N. Dormo, O. Ulbert and L. Gubicza, Desalination, 2002, 149, 267-268.

130 P. Izak, F. D. Bobbink, M. Hulla, M. Klepic, K. Friess, S. Hovorka and P. J. Dyson, ChemPlusChem, 2018, 83, 7-18.

131 X. Yan, S. Anguille, M. Bendah and P. Moulin, Sep. Purif. Technol. 2019, 222, 230-253.

132 J. Wang, J. Luo, S. Feng, H. Li Y. Wan and X. Zhang, Green Energy Env., 2016, 1, 43-61.

133 E. Rynkowska, K. Fatyeyeva and W. Kujawski, Rev. Chem. Eng., 2018, 34, 341-363.

134 T. J. Kim, A. Lang, A. Chikukwa, E. Sheridan, P. I. Dahl, M. Leimbrink, M. Skiborowski, and J. Roubroeks, Energy Procedia, 2017, 114, 17-24.

135 A. Bednar, N. Nemestóthy, P. Bakonyi, L. Fulop, G. Zhen, X. Lu, T. Kobayashi, G. Kumar, K. Xu, K. Belafi-Bako, Chem. Eng. J., 2016, 303, 621-626.

136 Y. Gu, I. Favier, C. Pradel, D. L. Gin, J. F. Lahitte, R. D. Noble M. Gomez, J. C. Remigy, J. Membr. Sci., 2015, 492, 331-339.

137 L. Zhang, Y. Li, Q. Liu, W. Li and W. Xing, J. Membr. Sci., 2019, 584, 268-281.

138 J. J. Li, Y. N. Zhou and Z. H. Luo, Progr. Polym. Sci., 2018, 87, 1-33.

139 B. Jiang, H. Zhang, L. Zhang, Y. Sun, L. Xu, Z. Sun, W. Gu, Z. Chen and H. Yang, Ind. Eng. Chem. Res., 2017, 56, 11817-11826.

140 C. X. Cao, J. Y. Yuan, J. P. Cheng and B. H. Han, Sci. Reports, 2017, 7, art. no. 3101

141 S. Montolio, G. Abarca, R. Porcar, J. Dupont, M. I. Burguete E. GarciaVerdugo and S. V. Luis, J. Mat. Chem. A, 2017, 5, 9733-9744.

142 R. Porcar, D. Nuevo, E. Garcia-Verdugo, P. Lozano, J. SanchezMarcano, M. I. Burguete and S. V. Luis, Chem. Commun., 2018, 54, 2385-2388.

143 H. H. Shi, K. X, Nie, B. Dong, M. Q. Long, H. Xu and Z. C. Liu, Chem. Eng. J., 2019, 361, 635-650.

144 K. S. Elvira, X. Casadevall i Solvas, R. C. R. Wootton and A. J. deMello, Nature Chem., 2013, 5, 905-915.

145 C. Yao, Y. Zhao and G. Chen, Chem. Eng. Sci., 2018, 189, 340-359.

146 P. L. Suryawanshi, S. P. Gumfekar, B. A. Bhanvase, S. H. Sonawane and M. S. Pimplapure, Chem. Eng. Sci., 2018, 189, 431-448.

147 V. Kumar and K. D. P. Nigam, Green Process Synth., 2012, 79-107.

148 Y. Zhao, C. Yao, G. Chen and Q. Yuan, Green Chem., 2013, 15, 446-452.

149 M. Rahman, T. Fukuyama, N. Kamata, M. Sato and I. Ryu, Chem. Commun., 2006, 2236-2238. 
150 J. Wang, S. Gu, H. Cui, L. Yang and X. Wu. Bioresour. Technol., 2013, 149, 367-374.

151 S. Wang, Z. Li, S. Sheng, F. Wu and J. Wang. J. Chem. Technol. Biotechnol., 2016, 91, 555-562.

152 D. Horii, T. Fuchigami and M. Atobe, J. Am. Chem. Soc., 2007, 129, 11692-11693.

153 I. Ryu, T. Fukuyama, M. Rahman and M. Sato, Synlett, 2008, 2, 151163.

154 S. Liu, T. Fukuyama, M. Sato and I. Ryu. Org. Process Res. Dev., 2004, 8, 447-481.

155 L. Bai, Y. Fu and Y. J. Flow Chem., 2017, 7, 52-56.

156 P. Kluson, P. Stavarek, V. Penkavova, H. Vychodilova, S. Hejda and M. Bendova, Chem. Eng. Process., 2017, 115, 39-45.

157 R. Kukawka, A. Pawlowska-Zygarowicz, M. Dutkiewicz, H. Maciejewski and M. Smiglak, RSC Adv., 2016, 6, 61860-61868.

158 M. Jankowska-Wajda, R. Kukawka, M. Smiglak and H. Maciejewski, New J. Chem., 2018, 42, 5229-5236.

159 F. J. Keil, Rev. Chem. Eng., 2018, 34, 135-200.

160 R. Karande, A. Schmid and K. Buehler, Org. Process Res. Dev., 2016, 20, 361-370.

161 U. Novak and P. Znidarsic-Plazl, Green Process. Synth., 2013, 2, 561-568.

162 A. Pohar, I. Plazl and P. Znidarsic-Plazl, Lab Chip, 2009, 9, 33853390.

163 U. Novak, A. Pohar, I. Plazl and P. Znidarsic-Plazl, Sep. Purif. Technol., 2012, 97, 172-178.

164 A. Gong, S. Gu, J. Wang, S. Sheng and F. Wu, Bioresour. Technol., 2015, 193, 498-506.

165 Y. X. Qiao, W.B. Ma, N. Theyssen, C. Chen and Z. S. Hou, Chem. Rev., 2017, 117, 6881-6928.

166 Z. G. Lv, Y. F. Jiang, C. Zhou, Z. M. Guo, X. L. Ma,Q. Chen, T. Nie and H. B. Song, J. Mol. Catal. A. Chem, 2016, 415, 89-95.

167 X. L. Chen, B. Souvanhthong, H. Wang, H. W. Zheng, X. H. Wang and M. X. Huo, Appl. Catal. B Environ., 2013, 138, 161-166.

168 W. Zhu, Y. Yu, H. Yang, L. Hua, Y. Qiao, X. Zhao and Z. Hou, Chem. Eur. J., 2013, 19, 2059-2066.

169 J. Z. Chen, L. Hua, W. W. Zhu, R. Zhang, L. Guo, C. Chen, H. M. Gan, B. N. Song and Z. S. Hou, Catal. Commun., 2014, 47, 18-21.

170 D. Mecerreyes, Prog. Polym. Sci., 2011, 36, 1629-1648.

171 S. Montolio, L. Gonzaez, B. Altava, H. Tenhu, M. I. Burguete, E. Garcia-Verdugo and S. V. Luis, Chem. Commun., 2014, 50, 10683-10686.

172 E. Karjalainen, D. F. Izquierdo, V. Marti-Centelles, S. V. Luis, H. Tenhu and E. Garcia-Verdugo, Polym. Chem., 2014, 5, 1437-1446.

173 P. Lozano, J. M. Bernal and M. Vaultier, Fuel, 2011, 90, 3461-3467.

174 P. Lozano, J. M. Bernal and A. Navarro, Green Chem. 2012, 14, 30263033.

175 P. Lozano, J. M. Bernal, G. Sánchez-Gómez, G. López-López and M. Vaultier. Energy Environ. Sci, 2013, 6, 1328-1338.
176 P. Bonhote, A. P. Dias, N. Papageorgiou, K. Kalyanasundaram and M. Graltzel. Inorg. Chem. 1996, 35, 1168-1178.

177 P. Lozano, J. M. Bernal, A. Lajarin, D. Romera, E. Garcia-Verdugo, G. Sanchez-Gomez, M. Pucheault, M. Vaultier, M. I. Burguete and S. V. Luis, Curr. Green Chem., 2014, 1, 145-154.

178 E. Alvarez, J. Rodriguez, R. Villa, C. Gomez, S. Nieto, A. Donaire and P. Lozano, ACS Sustain. Chem. Eng., 2019, 7, 13307-13314.

179 P. Lozano, J. M. Bernal, R. Piamtongkam, D. Fetzer and M. Vaultier, ChemSusChem, 2010, 3, 1359-1363.

180 P. Lozano, C. Gomez, A. Nicolas, R. Polo, S. Nieto, J. M. Bernal, E. Garcia-Verdugo and S. V. Luis, ACS Sustain. Chem Eng., 2016, 4, 61256132.

181 P. Lozano, J. M. Bernal, C. Gomez, E. Alvarez, B. Markiv, E. GarciaVerdugo and S. V. Luis, Catal. Today, 2019, doi.org/10.1016/j.cattod.2019.01.073.

182 Y. Y. Huang, J. S. Ren, and X. G. Qu, Chem. Rev. 2019, 119, 43574412. 